\title{
Advances in the Study of Moving Sediments and Evolving Seabeds
}

\author{
Alan G. Davies · Peter D. Thorne
}

Received: 25 November 2007/ Accepted: 23 July 2008/Published online: 27 August 2008

(C) The Author(s) 2008. This article is published with open access at Springerlink.com

\begin{abstract}
Sands and mud are continually being transported around the world's coastal seas due to the action of tides, wind and waves. The transport of these sediments modifies the boundary between the land and the sea, changing and reshaping its form. Sometimes the nearshore bathymetry evolves slowly over long time periods, at other times more rapidly due to natural episodic events or the introduction of manmade structures at the shoreline. For over half a century we have been trying to understand the physics of sediment transport processes and formulate predictive models. Although significant progress has been made, our capability to forecast the future behaviour of the coastal zone from basic principles is still relatively poor. However, innovative acoustic techniques for studying the fundamentals of sediment movement experimentally are now providing new insights, and it is expected that such observations, coupled with developing theoretical works, will allow us to take further steps towards the goal of predicting the evolution of coastlines and coastal bathymetry. This paper presents an overview of our existing predictive capabilities, primarily in the field of non-cohesive sediment transport, and highlights how new acoustic techniques are enabling our modelling efforts to achieve greater sophistication and accuracy. The paper is aimed at coastal scientists and managers seeking to understand how detailed physical studies can contribute to the improvement of coastal area models and, hence, inform coastal zone management strategies.
\end{abstract}

Keywords Waves - Currents - Wave-current interaction - Modelling turbulence and coherent structures - Seabed boundary layer - Sediment transport .

Coastal morphological modelling

\footnotetext{
A. G. Davies $(\bowtie)$

School of Ocean Sciences, College of Natural Science, Bangor University, Menai Bridge, Anglesey LL59 5AB, UK

e-mail: a.g.davies@bangor.ac.uk

P. D. Thorne

Proudman Oceanographic Laboratory, Joseph Proudman Building, 6 Brownlow Street, Liverpool L3 5DA, UK

e-mail: pdt@pol.ac.uk
} 


\section{Introduction}

The mobility of seabed sediments has profound ramifications for the large proportion of the world's population that live and work in close proximity to the coastline. The stability of navigation channels has been of concern to mariners over millennia. In more recent times, the appearance of super-tankers and large container vessels in shallow coastal waters has brought the issue of channel mobility and predictability into sharp focus on account of the environmental hazards posed by major navigation accidents. Frequent surveying and dredging of the approach channels to ports is very costly, but clearly necessary. The laying of offshore gas and oil pipelines has raised further issues of strategic and economic importance linked to the stability of the seabed. Nowadays, climate change, involving projected sea-level rise and increased storminess, is forcing us to think hard about strategies, 'green' or otherwise, for the defence of the coastline itself. Half of Europe's wetlands are expected to disappear by 2020 (European Commission 2006). In the UK context, a substantial loss of the shoreline is predicted over the next 20 years, much of which is presently significant wildlife habitat.

To address future issues in the coastal zone without considering the likely shape of the seabed would be imprudent. A change in the offshore seabed bathymetry can lead via wave and tidal action to severe, often unwanted, impacts at the coastline itself. The loss of the village of Hallsands on the South coast of Devon, U.K., over a 25 year period from 1890, occurred due to the removal of shingle from the nearshore zone (Web 1). Our present day demands for sand and gravel are growing inexorably. The predicted requirement for sand for building construction, artificial islands, beach nourishment, etc., is estimated to be one hundred to one thousand million $\mathrm{m}^{3}\left(10^{8}-10^{9} \mathrm{~m}^{3}\right)$ (i.e. up to $1 \mathrm{~km}^{3}$ ) per country surrounding the North Sea over the next 10-20 years (Van Rijn et al. 2005). Huge projects are being undertaken worldwide, for example in Qatar where a new airport, $22 \mathrm{~km}^{2}$ in area, is being built by reclaiming land using dredged material. This material is being supplied by dredging approximately $6 \times 10^{7} \mathrm{~m}^{3}$ of sediment from nearshore areas. Projects on this scale pose the question-where do we get the sand from without destabilizing the coastal zone and the shoreline itself? The cheapest option is usually to take the sand from the immediate foreshore. But in order to ensure the stability of the nearshore region and of the coastline, it is actually necessary to go far out to sea, despite the extra costs that are involved (Van Rijn et al. 2005).

The scientific issues behind these practical problems are interesting ones that come back to the same underlying question: can we understand and then predict the movement of seabed sediments? A prerequisite for the successful modelling of sediment transport is the representation of the flow itself and, in particular, the modelling of the effects of currents and waves. The nature of turbulent mixing in steady 'boundary layer' flows has been understood since the 1930s. At this time, when most interest was on river flows, key concepts such as the 'threshold' of sediment motion, and the shape of the suspended sediment concentration profile, were linked to the bed shear stress and its prediction, often using measured logarithmic velocity profiles. The subsequent detailed measurement of turbulence became possible from the 1970s onwards (Heathershaw 1974), leading to a much more detailed understanding of mixing processes and also providing the rationale for the use of (numerical) turbulence models of increasing complexity for the prediction of sediment transport rates (Davies 1990).

The complementary role of waves in mobilising and transporting sediment in coastal waters was studied in detail from the 1950 s, mainly by coastal engineers. However, only during the late 1970s and 1980s were serious attempts made to bring together the two 
strands of sediment transport research involving, firstly, currents and, secondly, waves (Grant and Madsen 1979; Fredsøe 1984; Davies et al. 1988). The combined effect of waves and (tidal) currents represents the key issue in sediment transport research in the coastal zone. Thus detailed 'process' models were developed of the interaction between waves and currents in the seabed boundary layer on small local scales (representing $1 \mathrm{~m}^{2}$ of seabed, say), together with new formulations for predicting the shapes of the resulting bed forms, in order to quantify sediment transport rates in combined wave-current flows. These transport rates can be one or two orders of magnitude greater than the transport by currents alone due to the ability of waves to stir up the bottom sediments (Van Rijn 1993). Major advances followed in the 1990s involving the enhancement of our observational capabilities with regard to the sediments, both in the field (Vincent and Hanes 2002) and also in small- and large-scale laboratory facilities (Ribberink and Al-Salem 1995). The challenge posed to earlier models by these new data has led on to a new generation of sophisticated, well validated modelling methods (Davies et al. 1997; Davies et al. 2002).

These models are now believed to have the correct general behaviour over the wide range of wave, current and sediment conditions found in typical coastal areas. This is an important prerequisite for successful 'morphological modelling' where the aim is to predict the evolution of the seabed on medium time scales of months, and possibly for longer. Such models are based on a realistic climate of waves superimposed on tidal currents, taking into account sea level variations consequent upon the waves themselves and also storm surge activity. Rather than relying on the observation of long-term trends on site, the increasingly favoured approach has been to embed small-scale local sediment transport models within the larger morphological models, in order to describe the 'sub-grid scale' processes that cannot be represented directly by these models. The numerical grids used in the morphological simulations may be of the order of 100s of metres in offshore model areas of a few square kilometres, reducing to 5-10 $\mathrm{m}$ in shallow inshore areas, for example near bathymetric features of particular interest. Despite this quite high spatial resolution in area models, which is accompanied by quite short model time steps (say 15 min for the 'morphodynamic time step'), the local sediment transport processes themselves take place on much smaller spatial and temporal scales. Although the new generation of morphological models is still in its infancy, and is still constrained by computer run times for longterm simulations, it has achieved some notable successes (Van Rijn et al. 2005), and the model outcomes allow critical tests of our ability to represent detailed sediment transport processes realistically.

The sediments (sand and mud) comprising the seabed have been in a process of slow change and redistribution over millennia. Despite this, on a time scale of, say, a decade, we like to think in terms of a 'natural equilibrium' existing in a coastal area. The consequences of disturbing this natural equilibrium may be felt not only in the immediate vicinity of the disturbance but in a more extensive area up and down the coast. Changing the offshore bathymetry can alter the tidal current patterns but, more importantly with regard to the sediments, it can change the distribution of waves in the nearshore zone. This is important because it is here, in very shallow water, that waves not only steepen and break, releasing their energy, but they also set up strong currents (e.g. longshore currents and undertow) that transport large amounts of sediment. The prediction of the consequent changes is the challenge faced by morphological modellers.

The present article is aimed at providing coastal scientists and managers with some perspectives as to how successful we have been to date in carrying out detailed local sediment transport process studies, and then translating the outcomes of this research into larger scale coastal area sediment transport models. In Section 2 we introduce the context 
and concepts involved in sediment transport research. In Section 3, we explore the variety of local process studies that have been carried out for rippled and plane seabeds, and give an assessment of our predictive capabilities. Then, in Section 4, we show how the new generation of acoustic instruments is enabling us to gain greater understanding of the physical processes of sediment transport on field scales. In Section 5, the use of morphological models is discussed with emphasis on the challenges still faced in parameterising small scale processes into coastal area modelling systems.

\section{Sediment Transport: Context and Concepts}

\subsection{The Hydraulic Context}

There is an essential difference between the sediment transport processes that occur above rippled and plane sand beds. Both types of seabed, as well as the transition state between them, are of importance in coastal engineering. It is necessary, therefore, to define the boundary delineating the respective regimes. This is normally done in a coastal context with reference to the motions induced by the surface waves. According to the classical linear wave theory, if the wave height is $H(=2 a)$, the wave angular frequency is $\omega(=2 \pi / T$ where $T$ is the wave period), and the mean water depth is $h$ above a horizontal seabed, then the velocity amplitude $\left(U_{0}\right)$ and particle excursion amplitude $\left(A_{0}\right)$ just above the thin frictional seabed boundary layer are given by:

$$
U_{0}=\frac{a \omega}{\sinh k h} \quad \text { and } \quad A_{0}=\frac{U_{0}}{\omega}
$$

(see Fig. 1). Here the surface wave number $k(=2 \pi / \lambda$ where $\lambda$ is the surface wavelength) satisfies the wave dispersion equation: $\omega^{2}=g k \tanh k h$, where $g$ is the acceleration due to gravity. The layer of frictional influence above a plane seabed, referred to as the 'wave boundary layer', has a thickness corresponding to $2-4 \%$ of $A_{0}$. Beneath sea waves, this boundary layer is very thin $O(0.01-0.1 \mathrm{~m})$ and, consequently, the (turbulent) mixing within it is localised and intense.

A central issue in the modelling of boundary layer flows is the specification of the seabed 'equivalent' roughness $\left(k_{\mathrm{s}}\right)$, which affects significantly the bed shear stress and also

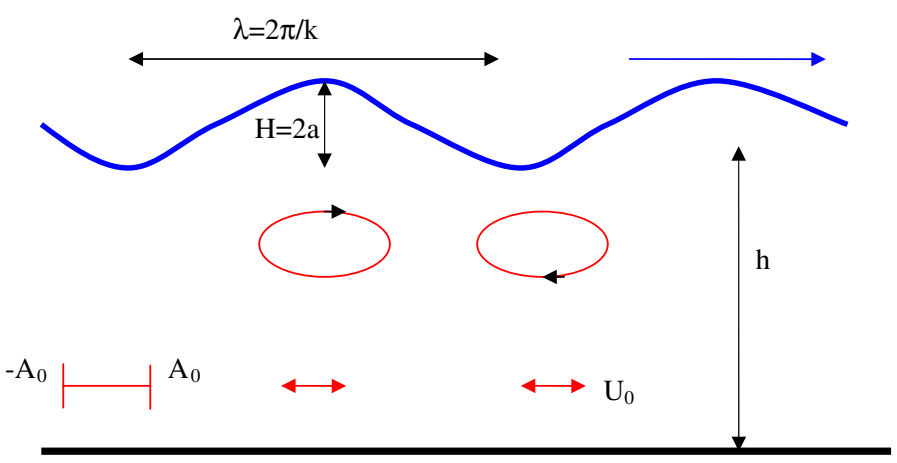

Fig. 1 Definition sketch: surface progressive waves above a plane bed. The direction of propagation is towards the right; $H=$ wave height, $a=$ wave amplitude, $\lambda=$ wavelength, $k=$ wave number, $h=$ mean water depth, $A_{0}=$ near-bed orbital excursion amplitude, $U_{0}=$ near-bed velocity amplitude 
the type of flow (laminar, transitional or turbulent) (Nielsen 1992; Van Rijn 1993). Depending upon the substrate involved, the roughness $k_{\mathrm{s}}$ is determined by some combination of the sediment grain size, the bed form dimensions (ripple height $\eta$ and wavelength $\lambda$ ) and, in the case of mobile sediment, the roughness associated with the moving sand layer (Grant and Madsen 1982). Moreover, the roughness $k_{\mathrm{s}}$ is linked to the structure of the (turbulent) near-bed flow by the relationship $k_{\mathrm{s}}=30 z_{0}$ where $z_{0}$ is the 'bed roughness length-scale' that defines the level of no motion on a logarithmic velocity profile.

The presence or absence of ripples on the seabed is the key consideration with regard to $k_{\mathrm{s}}$. Steep sand ripples are formed by relatively low surface waves in relatively deep water (i.e. in typical offshore conditions with $a / h \ll 1$ ). Such ripples present large values of $k_{\mathrm{s}}$. They tend to be long crested (two-dimensional), and to have steepness $(\eta / \lambda)$ greater than about 0.12 (often >0.15) (see e.g. Fredsøe and Deigaard 1992; Nielsen 1992). Beneath steeper waves in shallower water (typically, at the edge of the surf zone) the ripples start to become washed out; their steepness decreases, causing $k_{\mathrm{s}}$ to decrease, and they may become shorter crested (with 'transitional' 2D-3D profiles). Finally, beneath very steep and breaking waves, the ripples are washed away completely, the bed becomes plane ('sheet flow' regime), and the bed roughness $k_{\mathrm{s}}$ decreases still further.

Many empirical formulae for $k_{\mathrm{s}}$ have been suggested since, in practical sand transport modelling, $k_{\mathrm{s}}$ must be either specified or parameterised. Mathisen and Madsen (1996a, b, 1999) carried out detailed studies of the bed roughness in the laboratory by measuring wave dissipation rates above fixed 2D bed roughness, while Styles and Glenn (2002) proposed models for the prediction of the ripple dimensions and the bed roughness. Typically, above a plane sand bed in laboratory conditions, $k_{\mathrm{s}}=2.5 D$ where $D$ is the grain size (Soulsby 1997) while, above rippled sand beds, $k_{s}=25 \eta \eta / \lambda$ (Nielsen 1979). The appearance of the ripple steepness $\eta / \lambda$ in the expression for $k_{\mathrm{s}}$ has a dynamical significance related to the presence $(\eta / \lambda \geq 0.12)$ or absence $(\eta / \lambda \leq 0.05)$ of flow separation over the bed forms in the respective cases of steep and low ripples. The former case of steeply rippled beds is typical of small scale laboratory (wave flume) experiments, above which vortex formation and shedding occur in each wave half cycle, and here the roughness $k_{\mathrm{s}}$ corresponds to about 3-4 ripple heights $\left(k_{\mathrm{s}}=3 \eta-4 \eta\right)$. The latter case is typical of measurements made beneath waves, and also wave-current flows, in larger scale wave basins (Van Rijn 1993). Here the flow tends to follow the bed shape, such that the absence of significant flow separation and eddy shedding presents a more 'dynamically plane' bed. This gives rise, in turn, to a lower observed roughness $k_{\mathrm{s}}$ equal approximately to the ripple height $\left(k_{\mathrm{s}}=0.5 \eta-\eta\right)$. These lower $k_{\mathrm{s}}$ values are attributable also to irregularities in the ripples formed on larger laboratory (basin) scales, e.g. along-crest irregularities in the ripple profile that promote 2D-3D flow structures, in contrast to the predominantly 2D flow above steep longer-crested ripples. Use of the lower range of $k_{\mathrm{s}}$ values is probably to be expected in most field applications, though steep ripples can occur in the field. Van Rijn (2005) argued that, since a generally accepted, accurate, predictor of ripple characteristics is not yet available, the prediction of $k_{\mathrm{s}}$ from estimated ripple dimensions will not lead to very accurate results. However, most investigators base $k_{\mathrm{s}}$ directly on the ripple dimensions; for example, the prediction of the bed roughness $k_{\mathrm{s}}$, via the ripple dimensions $\eta$ and $\lambda$, forms a key part of the methodology in the 'UWB Sand Transport Model' (see Sect. 3.1).

The sequence of ripple occurrence and wash-out in increasingly active wave conditions is summarised in Table 1 in terms of the non-dimensional 'relative roughness' $A_{0} / k_{\mathrm{s}}$, where $A_{0}$ is the near-bed orbital excursion amplitude. As the waves become larger (increasing $A_{0}$ ), causing wash out (decreasing $k_{\mathrm{s}}$ ), the relative roughness $\left(A_{0} / k_{\mathrm{s}}\right)$ increases. Equivalent approximate ranges of the wave Reynolds number RE $\left(=A_{0}^{2} \omega / v\right)$, where $v=$ kinematic 
Table 1 Bed form characteristics in the coastal zone together with the associated hydrodynamic parameter ranges

\begin{tabular}{lllll}
\hline Bed form characteristics & 2D steep ripples & 2D and 3D low ripples & Washed-out ripples & Plane bed \\
\hline Ripple steepness $\eta / \lambda$ & $\eta / \lambda \geq 0.15$ & $0.05<\eta / \lambda \leq 0.15$ & $\eta / \lambda<0.05$ & $\eta / \lambda=0$ \\
Relative roughness $A_{0} / k_{s}$ & $\mathrm{O}(1)$ & $\mathrm{O}(1-10)$ & $\mathrm{O}(10-100)$ & $\mathrm{O}(100-1000)$ \\
Reynolds number $R E$ & $\mathrm{O}\left(10^{3}-10^{4}\right)$ & $\mathrm{O}\left(10^{4}-10^{5}\right)$ & $\mathrm{O}\left(10^{5}\right)$ & $\mathrm{O}\left(10^{6}-10^{7}\right)$ \\
Peak Shields parameter $\hat{\theta}$ & $0.05-0.2$ & $0.2-0.6$ & $0.6-0.8$ & $>0.8$ \\
\hline
\end{tabular}

viscosity, and also the peak non-dimensional bed shear stress or Shields parameter $(\hat{\theta})$, are also shown in Table 1 . Here $\hat{\theta}=\frac{\hat{\tau}_{0}}{\left(\rho_{s}-\rho\right) g D}$ where $\hat{\tau}_{0}$ is the peak bed shear stress during the wave cycle, $\rho_{\mathrm{s}}$ and $\rho$ are the densities of the sediment and water respectively, and $D$ is the median grain diameter.

The type of oscillatory boundary layer flow expected in different ranges of $A_{0} / k_{\mathrm{s}}$ and RE was reviewed by Davies and Villaret (1997). Much of our existing knowledge has been derived from laboratory experiments, and also modelling studies, carried out either for the rippled bed regime $\left(A_{0} / k_{\mathrm{s}} \sim 1\right)$ or for the plane bed regime (large $\left.A_{0} / k_{\mathrm{s}}\right)$. Surprisingly little is known about the intermediate, 'very rough bed' regime $\left(A_{0} / k_{\mathrm{s}}=5-30\right)$, which is unfortunate since many situations of practical importance in the sea occur in this regime. However, the present authors, among others, have started to fill these gaps in knowledge by making observations in field-scale facilities (see Sect. 4).

As indicated above, fundamentally different physical processes determine sand transport rates above plane and rippled sand beds in oscillatory flows induced by surface waves. Above plane beds, momentum transfer occurs primarily by turbulent diffusion. As a result of boundary layer dynamics, the peak bed shear stress during the wave cycle occurs just ahead (by typically $20-30^{\circ}$ ) of the peak 'free-stream' velocity in both (onshore and offshore) wave half-cycles. At these instants sediment is mobilised and then, due to the turbulence generated in the near-bed layer, is entrained upwards (as illustrated in Fig. 2). As the turbulence intensity then decreases around flow reversal, the sediment tends to settle back to the bed. The resulting suspended sediment concentration profile represents the balance between upward diffusion and downward settling of sediment. Beneath steep waves the velocity field is asymmetrical and net sediment transport, normally in the onshore direction of wave propagation, can then occur as a result of the mechanisms highlighted in Sect. 3.1.

In contrast, in the bottom part of the boundary layer above steeply rippled beds, momentum transfer and the associated sediment dynamics are dominated by coherent, periodic vortex structures; above this layer of thickness about 1-2 ripple heights the coherent motions break down and are replaced by random turbulence. The effect of this is that sand is entrained into suspension to considerably greater heights above rippled beds than above plane beds. In addition, the phase of sand pick-up from the bottom during the wave-cycle is also significantly different above rippled beds, with pick-up being linked to the phase of vortex shedding. The vortex shedding process, from which suspended sediment transport processes may be inferred, is illustrated in Fig. 3. A spinning parcel of sediment laden water, $v_{1}$, is formed on the lee side of the ripple around the time of the peak positive (onshore) velocity in the wave cycle, as shown Fig. 3a, b. This sediment rich vortex is then thrown up into the water column at flow reversal, Fig. 3c, d, carrying sediment well away from the bed and allowing it to be transported (offshore) by the flow. At the same time a sediment rich vortex, $v_{2}$, is formed on the opposite side of the ripple due 

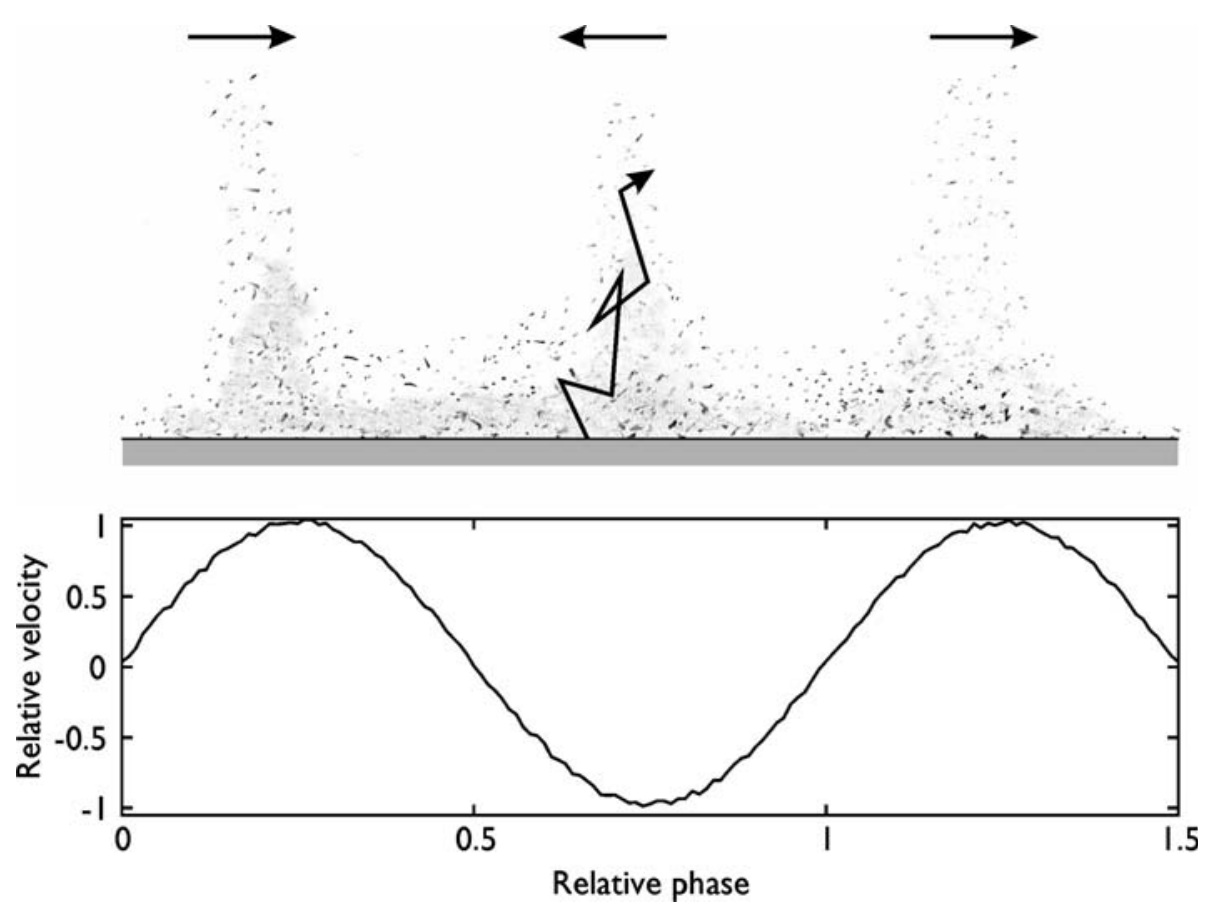

Fig. 2 Turbulent mixing processes in oscillatory flow above a plane bed. Here maximum sediment entrainment occurs at the phases of peak velocity (shown by the arrows), and hence bed stress, as illustrated
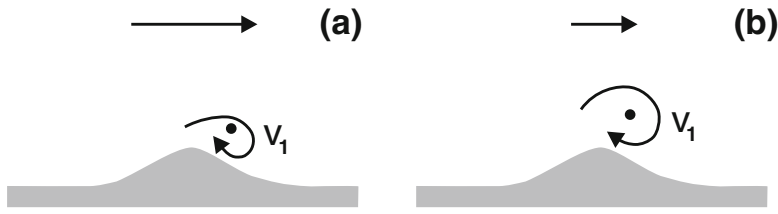

(d)
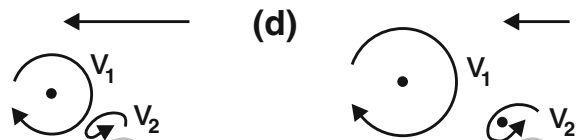

(e)

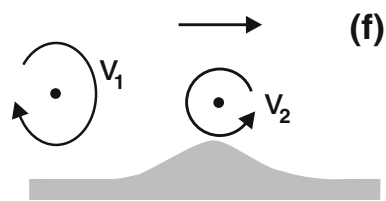

(c)

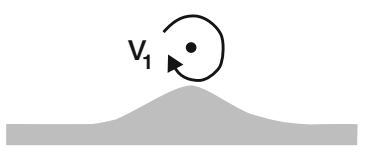

(f)

Fig. 3 Schematic of vortex shedding above a rippled bed. The horizontal arrow at the top of each figure represents the oscillating near-bed velocity above the vortex layer. The flow in the 'positive' (left-to-right: f, a, b) half-cycle induces a clockwise-rotating vortex $v_{1}$ which grows in size before being shed at flow reversal. The flow in the succeeding 'negative' (right-to-left: c, b, e) half-cycle then induces an anticlockwise-rotating vortex $v_{2}$ which is shed, in turn, at flow reversal

to the reversed flow. As shown in Fig. 3d-f, $v_{2}$ grows, entrains sediment, becomes detached and moves over the crest at the next flow reversal carrying sediment into suspension. The main feature of the vortex mechanism above steeply rippled beds is that 
sediment is carried up into the water column twice per wave cycle at flow reversal. Moreover, under steep asymmetrical surface waves, vortex $v_{1}$ becomes stronger than vortex $v_{2}$ with the potentially important consequence of an offshore 'pumping' of the suspended sediment. In other words, the net sand transport rate beneath asymmetrical waves can be in the negative (offshore) direction despite the larger positive (onshore) orbital velocities.

More generally, sediment transport depends upon three interacting components namely the characteristics of the mobile sediment, the bed forms and the forcing hydrodynamics. Vital here is the idea that beneath low waves the seabed is rippled, while under large waves (e.g. storm waves) it becomes plane, and that very different mechanisms of sediment entrainment and transport operate in these regimes. Flow separation and vortex generation due to oscillatory (wave-induced) flow over ripples on the seabed influence the suspension of sediment. Further, the size and shape (height, wavelength, asymmetry) of the ripples contributes to the overall flow resistance (through $k_{\mathrm{s}}$ ) and, hence, to the flow structure in the boundary layer. Yet the ripples themselves are a result of the local sediment transport, completing the triad of interactions and feedbacks (Fig. 4). In practice, the seabed may be considered to be 'self-regulating' in the sense that the efficient transporting mechanisms of the rippled-bed regime at low flow stages are replaced, for larger storm waves, by the less efficient transporting mechanisms of the sheet flow regime. Interestingly, therefore, the bed is to some extent self-protecting against the impact of potentially destructive storm waves (as illustrated later in Fig. 6).

\subsection{Models and Concepts}

A range of 'research' and 'practical' models has been developed to simulate sediment transport in the plane and rippled bed regimes (see Davies et al. 2002). Essentially, 'research' models aim to represent the detailed physical processes involved in sand transport by waves and currents, including intra-wave transport processes. They are developed for a particular transport regime (e.g. sheet flow above a plane bed), and they normally resolve the vertical structure (and also, in some cases, the horizontal structure) of the velocity and sediment concentration fields. Since research models normally require lengthy computation times, they tend not to be implemented in coastal-area morphological models involving many grid points. Instead, more 'practical' models are used for this purpose; these are simpler prediction schemes that either do not resolve the spatial and temporal structure of the velocity and concentration fields or, if they do so, employ simplified and prescriptive approaches. By their nature, practical models are usually aimed at covering a wide range of conditions; they are robust and easy to compute, and they can therefore be implemented relatively easily in coastal modelling systems. However such models normally omit key mechanisms, for example those arising from intra-wave processes, that may have important, and sometimes unexpected, practical consequences.

Fig. 4 The interacting 'sediment triad' showing schematically the interrelationship between the seabed, waves and currents, and the movement of suspended sediments

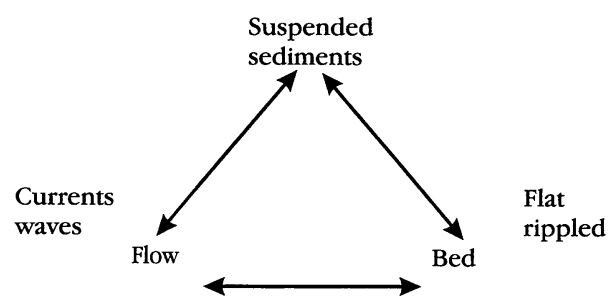


Thus a particularly important distinction between research and practical models is that, while research models determine both the 'wave-' and 'current-related' components of the suspended load transport, practical models usually determine only the 'current-related' component. The current-related transport, which is often the dominant component, follows approximately the direction of the mean flow (Davies and Villaret 2002). However, the wave-related component, which arises from intra-wave processes, can alter the net transport rate substantially in both magnitude and direction. This is particularly so for coarser sand grains confined to the near-bed oscillatory boundary layer.

The respective components of the total sand transport rate are defined as follows. The instantaneous velocity component $(U)$, with which the sediment grains are normally assumed to be transported horizontally in the x-direction, and the volumetric concentration $(C)$, are written respectively:

$$
U=u+u_{\mathrm{p}}+u^{\prime} \quad \text { and } \quad C=c+c_{\mathrm{p}}+c^{\prime}
$$

where both $U$ and $C$ are defined at height $z$ above the bed, and where any intra-ripple variations are assumed here for simplicity to have been spatially averaged over the ripple length scale. The time-mean components in Eq. 2.2 are $u=\langle U\rangle$ and $c=\langle C\rangle$ where anglebrackets denote averaging over a large (integral) number of wave periods, subscript $\mathrm{p}$ denotes the periodic components and a dash denotes the turbulent components (although $U$ is written here as the velocity component in the $x$-direction, it may alternatively be regarded as a $2 \mathrm{D}$ vector quantity defining the horizontal velocity field).

The 'true' cycle-averaged sediment flux at level $z$ is given approximately by:

$$
\langle U C\rangle \approx u c+\left\langle u_{\mathrm{p}} c_{\mathrm{p}}\right\rangle
$$

where the small turbulent contribution $\left\langle u^{\prime} c^{\prime}\right\rangle$ has been neglected. In Eq. 2.3 the term $u c$ corresponds to the 'current-related' contribution to the 'true' net transport, and the term $\left\langle u_{\mathrm{p}} c_{\mathrm{p}}\right\rangle$ to the 'wave-related' contribution. This latter contribution has been measured in the studies of, for example, Murray et al. (1991) and Ribberink and Al-Salem (1995). An example showing vertical profiles of the wave-related and true sediment flux beneath asymmetrical waves is included in Sect. 3.

The net suspended flux, $q_{\mathrm{s}}$, averaged over the depth from the 'reference level' $z=a$ to the mean water surface level $z=h$ is given by:

$$
q_{\mathrm{s}}=\int_{a}^{h}\langle U C\rangle \mathrm{d} z \approx \int_{a}^{h}\left[u c+\left\langle u_{\mathrm{p}} c_{\mathrm{p}}\right\rangle\right] \mathrm{d} z
$$

Finally the total net transport rate $\left(q_{\mathrm{t}}\right)$ is given by:

$$
q_{\mathrm{t}}=q_{\mathrm{s}}+q_{\mathrm{b}}
$$

where $q_{\mathrm{b}}$ corresponds to the net bed load transport in the very near-bed height range $0<z<a$. Here level $z=0$ usually represents the notional, undisturbed, (mean) bed level. However, if the sheet flow layer is taken into account explicitly in a model, the integration range may involve levels below $z=0$ in order to include the effects of erosion and, hence, transport below the undisturbed bed level (Malarkey et al. 2003). The bed load commonly dominates the total transport for coarse sands, while the suspended load commonly dominates for fine sands. If the mean mass transport rate $\left(Q_{\mathrm{t}}\right)$ is required, the respective qterms must be multiplied by the sediment density $\rho_{\mathrm{s}}$.

In the next section, the types of model that have been developed to predict the transport components are reviewed; terminology is elaborated for readers who may be unfamiliar 
with it, some key papers are identified, and the state of the art in sand transport modelling is assessed.

\section{Modelling Sediment Transport above Plane and Rippled Beds}

\subsection{Plane Bed Phenomena and Modelling}

Sand transport in combined wave and current flows over a plane bed involves fluid velocities and sand concentrations that vary strongly with time during the wave cycle. Here unsteady 'intra-wave' models, based on analytical or numerical solution of the basic fluid momentum and continuity equations, in combination with the sediment mass balance (advection-diffusion) equation, have been developed to determine the velocity and sand concentration fields as functions of space and time. These detailed 'research' models generally include the potentially important 'wave-related' component $\left\langle u_{\mathrm{p}} c_{\mathrm{p}}\right\rangle$ of the transport (Eq. 2.3).

Instantaneous sand concentrations in suspension above a plane bed are usually obtained from the solution of the one-dimensional vertical (1DV) advection-diffusion equation, namely:

$$
\frac{\partial C}{\partial t}=\frac{\partial}{\partial z}\left(\varepsilon_{\mathrm{s}, \mathrm{z}} \frac{\partial C}{\partial z}+w_{\mathrm{s}} C\right)
$$

where $C=$ instantaneous, volumetric sand concentration; $w_{\mathrm{s}}=$ sediment settling velocity; $\varepsilon_{s, z}=$ sediment mixing coefficient (diffusivity) in the vertical $z$-direction; and $t=$ time. Here the respective terms on the right hand side of the equation relate to upward diffusion and downward advection (settling) of sediment, respectively, any imbalance between which can result in a time-rate-of-change in the concentration $(C)$. The fluid motion itself is described by the corresponding momentum balance equation (see Davies 1990).

Analytical or numerical solution of these equations requires expressions for the vertical component of the eddy viscosity $\left(v_{\mathrm{t}, \mathrm{z}}\right)$ representing the fluid turbulence, and hence the sediment diffusivity $\left(\varepsilon_{\mathrm{s}, \mathrm{z}}\right)$, together with boundary conditions for velocity and sand concentration at the bed. The simplest approach for the definition of the diffusivity coefficients is the traditional mixing length concept. Above plane rough beds this leads typically, in steady, depth-limited, channel flows, to a parabolic distribution for $\varepsilon_{\mathrm{s}, \mathrm{z}}(\propto z(1-z / h)$ where $h$ is the water depth). This reflects the increasing eddy length scale with increasing height above the bed, and then the reduction in this length scale due to the proximity of the free surface. An accompanying bed boundary condition for sediment concentration involves, typically, the application of an empirical or semi-empirical 'reference concentration' which expresses the (volumetric) sediment concentration $c_{\mathrm{b}}$ at a defined reference level, e.g. $z=2 D$ (Englelund and Fredsøe 1976; Zyserman and Fredsøe 1994); $c_{\mathrm{b}}$ typically increases as the Shields parameter increases up to a value of about $\theta=0.75$, and the value of $c_{\mathrm{b}}$ then 'saturates' at about 0.3 which is approximately one half of the stationary (undisturbed) bed concentration of about 0.6. Various models have been developed for unsteady flow, including the well-known analytical models of Madsen and co-workers (Madsen and Grant 1976; Grant and Madsen 1986; Glenn and Grant 1987). In unsteady flow, however, a conceptually better approach than use of a reference concentration is the use of a 'pick-up' function that models the sediment entrainment rate from the bed in isolation from deposition on to the bed ( $\mathrm{Li}$ and Davies 2001). Overviews of numerical 
models, developed mainly for the suspension layer, have been given by Davies et al. (1997), Dohmen-Janssen (1999) and Davies et al. (2002).

The various models available incorporate a range of detailed physical processes and/or parameterisations of these processes; for example, Li and Davies (2001) developed a 1DV, one-equation turbulent kinetic energy closure model that includes the effects of (i) graded sediment sizes, (ii) turbulence damping by sediment in suspension and (iii) hindered settling caused by high sediment concentrations. This 'UWB Sand Transport Model' was used to study transport beneath large symmetrical and asymmetrical waves. Davies and Villaret (2002) extended the use of this 1DV model to investigate the process of mean current 'veering' in cases in which waves are obliquely incident on a current, illustrating the level of detail that can be obtained from a contemporary sand transport research model. However such potentially important processes are not normally included in simpler, more practical, waveaveraged models, e.g. those commonly used in morphological modelling systems.

The results in Fig. 5 illustrate some typical research model outcomes, here for the case of an asymmetrical wave above a plane, rough, sand bed. The model is a standard $k-\varepsilon$ turbulence-closure (see Malarkey et al. (2003) for details of the formulation) in which both
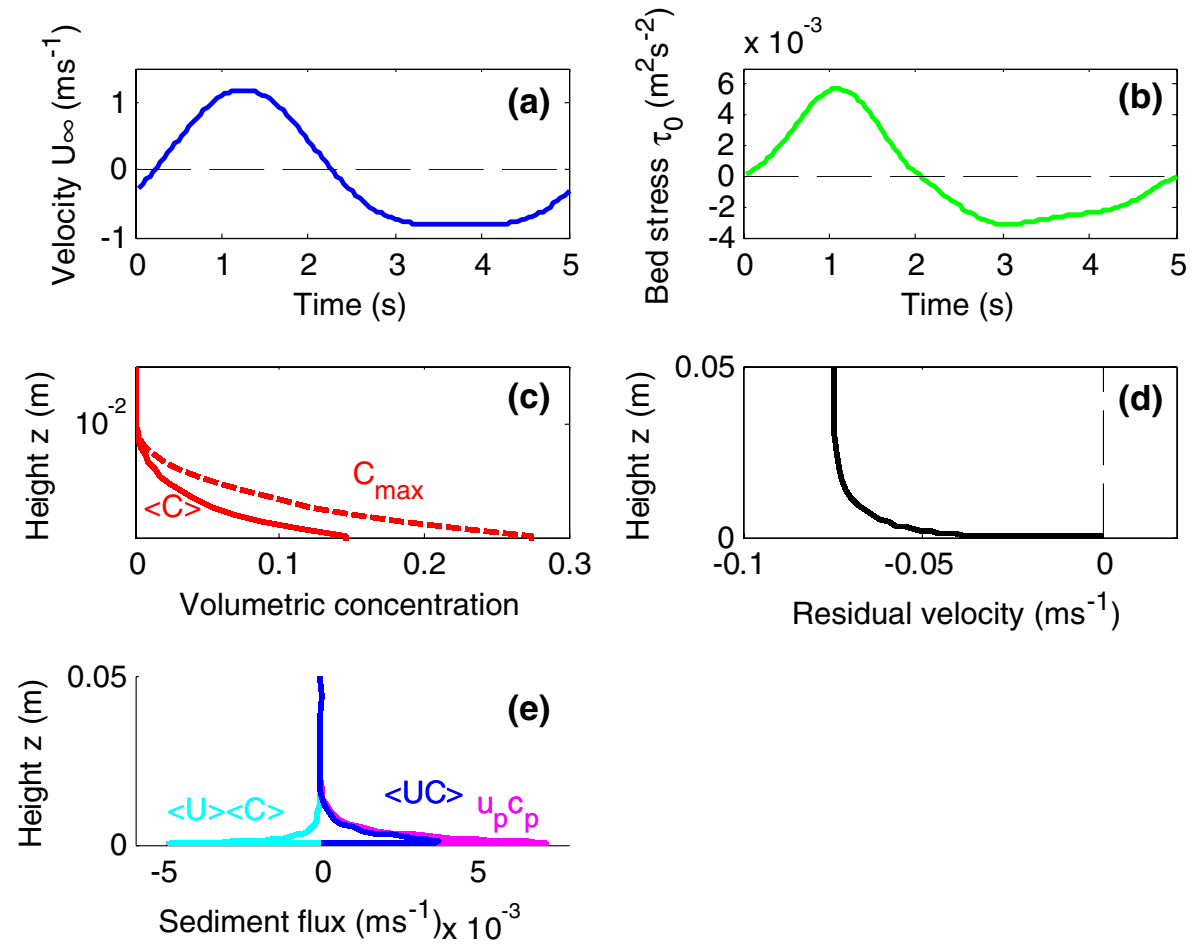

Fig. 5 Results from a $k-\varepsilon$ model of the boundary layer flow beneath asymmetrical waves (period $T=5 \mathrm{~s}$, first and second harmonics of velocity amplitude, $U_{1}=1.0 \mathrm{~m} \mathrm{~s}^{-1}, U_{2}=0.25 \mathrm{~m} \mathrm{~s}^{-1}$, respectively) above a plane sand bed (grain diameter $D=2.2 \times 10^{-4} \mathrm{~m}$, hence sediment settling velocity $w_{\mathrm{s}}=2.6 \times 10^{-2} \mathrm{~m} \mathrm{~s}^{-1}$ ). (a) shows the free-stream flow during the wave cycle, while (b) shows the corresponding bed shear stress. The cyclemean $(\langle C\rangle)$ and maximum instantaneous $\left(C_{\max }\right)$ concentration profiles are show in (c), and the 'offshore' residual velocity induced in the boundary layer is shown in (d). The resulting profiles of the 'true', 'current-related' and 'wave-related' components of the suspended sediment flux $\left(\langle U C\rangle,\langle U\rangle\langle C\rangle\right.$ and $\left\langle u_{p} c_{p}\right\rangle$, respectively) are shown in (e) 
the turbulent kinetic energy $(k)$ and the turbulent dissipation rate $(\varepsilon)$ (which acts as a proxy for the mixing length) are modelled in order to represent the vertical mixing of momentum and sediment in the boundary layer via the eddy viscosity $\left(v_{\mathrm{t}, \mathrm{z}}\right)$ and the sediment diffusivity $\left(\varepsilon_{\mathrm{s}, \mathrm{Z}}\right)$, respectively. The present formulation is one-dimensional vertical (1DV), such that the predicted (mean) motion is horizontally uniform (i.e. there are no vertical wave velocity effects). The wave period is $T=5 \mathrm{~s}$, and the (nominal) 'free-stream' velocity at the edge of the thin wave boundary layer is defined by first and second harmonics with respective amplitudes: $U_{1}=1.0 \mathrm{~m} \mathrm{~s}^{-1}, U_{2}=0.25 \mathrm{~m} \mathrm{~s}^{-1}$. This results in a larger velocity beneath the (implied) wave crest than beneath the trough (Fig. 5a) with maximum flow acceleration/deceleration occurring before and after the occurrence of peak crest velocity $\left(U_{\infty \text { max }}\right)$. The bed is assumed to comprise sand grains of size $D=0.22 \times 10^{-3} \mathrm{~m}$, such that the bed roughness length scale is $z_{0}=D / 12=1.83 \times 10^{-5} \mathrm{~m}$, at which height the velocity is zero; the corresponding sediment settling velocity is $w_{\mathrm{s}}=2.6 \times 10^{-2} \mathrm{~m} \mathrm{~s}^{-1}$. The predicted flow spins-up from a stationary state towards convergence.

Due to nonlinear processes in the wave boundary layer, the time-variation in the predicted bed shear stress (Fig. 5b) turns out to be rather more asymmetrical than that of the free-stream velocity itself $\left(\left|\tau_{0, \max } / \tau_{0, \text { min }}\right|=1.75\right.$, c.f. $\left.\left|U_{\infty, \max } / U_{\infty, \min }\right|=1.44\right)$. This asymmetry in the bed shear stress gives rise, in turn, to even greater asymmetry in the amount of sediment mobilised and entrained into suspension during successive wave halfcycles. Figure $5 \mathrm{c}$ shows the predicted concentration profile $\left(C_{\max }\right)$ at the instant of peak stress beneath the wave crest, together with the cycle-mean concentration profile $(\langle C\rangle)$.

A key feature of the boundary layer beneath asymmetrical waves involves the generation of a near-bed residual current (Davies and Li 1997). For the present horizontallyuniform flow this current arises entirely as a result of turbulence asymmetry in the two halves of the wave cycle; it has nothing to do with 'streaming' associated with vertical wave velocity effects, since these are absent here. What is the reason for the residual velocity? If horizontal velocity $(U)$, eddy viscosity $\left(v_{t}\right)$ and pressure forcing term in the wave $(x-)$ direction $\left(P_{x}=-\frac{1}{\rho} \frac{\partial p}{\partial x}\right.$ where $\mathrm{p}$ is the pressure), are each expressed in terms of a cycle-mean component $(<>)$ and a periodic component (subscript $p$ ):

$$
U=\langle U\rangle+u_{\mathrm{p}}, v_{\mathrm{t}}=\left\langle v_{\mathrm{t}}\right\rangle+v_{\mathrm{tp}}, \quad P_{\mathrm{x}}=\left\langle P_{\mathrm{x}}\right\rangle+P_{\mathrm{xp}},
$$

then, after time-averaging the equation of motion, the following equation is obtained:

$$
0=\left\langle P_{\mathrm{x}}\right\rangle+\frac{\partial}{\partial z}\left(\left\langle v_{\mathrm{t}}\right\rangle \frac{\partial\langle U\rangle}{\partial z}\right)+\frac{\partial}{\partial z}\left(\left\langle v_{\mathrm{tp}} \frac{\partial u_{\mathrm{p}}}{\partial z}\right\rangle\right)
$$

In the present absence of an imposed steady current, there is no mean pressure gradient $\left.\left(<P_{x}\right\rangle=0\right)$. Moreover the third term on the right-hand side turns out to be non-zero due to the correlated parts of the periodic eddy viscosity and velocity shear. The equation is thus balanced, via the second term, through the generation of a mean velocity component $(<U>)$. Essentially maximum turbulence intensity, and hence maximum $v_{\mathrm{t}}$, occurs at the time of maximum velocity shear beneath the wave crest. This gives rise to enhanced frictional resistance when the wave crest is passing, which is not countered by the weaker frictional effects that occur beneath the trough. The outcome is a residual mean current $(u=\langle U>)$ of significant magnitude in the negative (implied offshore) direction as illustrated in Fig. 5d.

The resulting profiles of the current-related sediment flux $(\langle U><C>)$, which is in the 'offshore' direction, and the wave-related flux $\left.\left(<u_{\mathrm{p}} c_{\mathrm{p}}\right\rangle\right)$, which is in the 'onshore' direction, are shown together with the true flux profile $\langle U C\rangle$ in Fig. 5e. The dominance of the 
wave-related contribution is clearly evident in the final outcome, namely a 'true' net flux that is in the onshore direction. After vertical integration of this true flux profile it turns out that the net suspended load transport rate is $q_{\mathrm{s}}=0.244 \times 10^{-4} \mathrm{~m}^{2} / \mathrm{s}$. This comprises $70 \%$ of the total onshore net sediment transport $\left(q_{\mathrm{t}}=q_{\mathrm{s}}+q_{\mathrm{b}}\right.$, Eq. 2.5) when the predicted net bed load contribution, $q_{\mathrm{b}}$, here equal to $0.108 \times 10^{-4} \mathrm{~m}^{2} / \mathrm{s}$, and also in the onshore direction, is taken into account. Although the example in Fig. 5 relates to (asymmetrical) waves alone, similar considerations apply in combined wave-current flows. The neglect of the wave-related component of the flux in most practical sand transport models represents an oversimplification that introduces inaccuracy and, potentially, may bias the outcome of morphological predictions.

The $k-\varepsilon$ turbulence model used above represents the suspended sediment load in considerable detail, but it treats the near-bed sediment transport in a more schematic way based on a classical bed load transport predictor. In some recent research models, greater emphasis has been given to 'sheet flow' conditions at the water-seabed interface. The sheetflow layer is the thin layer of high sediment concentration that occurs above plane, noncohesive, sediment beds in intense wave and current flow conditions. Sheet flow also contributes significantly to the (net) sediment transport beneath large (asymmetrical) waves, by analogy with the example in Fig. 5. The importance of grain collisions in the sheet-flow layer requires modelling approaches that are different from the standard diffusion concepts that are applied in the outer, low-concentration, suspension layer. Pioneering work in this area was carried out by Bagnold (1956) who developed the concept of a 'dispersive stress' in the sheet-flow layer, which absorbs the difference between the (larger) fluid stress applied at the top of the layer and the (smaller) critical threshold stress for sediment movement which may be inferred to exist at the bottom of the layer.

A complete modelling description of the sheet-flow layer requires, in principle, the use a 'two-phase' model in which the full collisional nature of the sediment transport process is taken into account (e.g. Kobayashi and Seo 1985; Asano 1990; Li and Sawamoto 1995; Villaret and Davies 1995; Jenkins and Hanes 1998; Villaret et al. 2000; Dong and Zhang 2002). However, despite the conceptual advantages of two-phase models, their complexity makes them unsuitable for practical sediment transport prediction. In fact, most 'research' models do not attempt to represent the sheet-flow layer in any detail, instead relying upon some form of parameterisation of the bed-load transport (Davies et al. 1997).

Wilson (1989) and, more recently, Sumer et al. (1996) related empirically the thickness of the sheet-flow layer $(\delta)$, and its equivalent roughness $\left(k_{\mathrm{s}}\right)$, to the applied Shields parameter $(\theta)$. Based on these results a new, quasi-steady, 1DV modelling approach was proposed for waves and currents by Malarkey et al. (2003). This model yields continuous, instantaneous, vertical profiles of velocity and sediment concentration from the stationary bed, through the high-concentration sheet-flow layer, up into the outer suspension layer. Importantly, it 'tracks' the erosion and deposition of the bottom, stationary sediment layer in relation to the combined amount of sediment present in the sheet-flow and suspension layers. Traditional models do not require this condition of continuity of mass to be satisfied explicitly as part of the formulation. Figure 6 shows results from the model of Malarkey et al. (2003) in comparison with a typical wave + current test carried out in an oscillatory flow tunnel by Dohmen-Janssen et al. (2001). The wave velocity amplitude and period are $U_{0}=1.47 \mathrm{~m} \mathrm{~s}^{-1}$ and $T=7.2 \mathrm{~s}$ respectively, and the current strength at height $z=0.1 \mathrm{~m}$ above the bed is $0.24 \mathrm{~m} \mathrm{~s}^{-1}$. The sand grain size is $D=0.21 \mathrm{~mm}$ with a corresponding settling velocity of $w_{\mathrm{s}}=2.6 \times 10^{-2} \mathrm{~m} \mathrm{~s}^{-1}$. Figure 6 a shows the modelled cycle-mean velocity profile which represents the data (dots) quite well in the outer boundary layer region; the transition between the sheet-flow and the suspension layer appears as a 'kink' in the model profile at a height of 
$z=1-2 \mathrm{~mm}$. Figure $6 \mathrm{~b}$ shows the equivalent cycle-mean concentration profile. The concentration in the outer suspension layer (defined as the layer in which $C<8 \%$ by volume, or $C \leq 200 \mathrm{~kg} \mathrm{~m}^{-3}$, corresponding here to $z \geq 10 \mathrm{~mm}$ ) which was measured with an OPCON probe is also described quite well by the model. The novel feature of this model, however, is its description of the high concentration layer below this $(C>8 \%)$ which extends right down to the stationary bed level. Here both the model and the data tend to a constant value of about $1.6 \times 10^{3} \mathrm{~kg} \mathrm{~m}^{-3}$; the measurements in the high concentration layer were made with a conductivity concentration meter (CCM).

Detailed 'research' models, such as those discussed above, commonly suffer from the disadvantage of requiring long run times even for individual calculations, and they also may not operate reliably outside the wave-current-sediment parameter range for which they were developed and validated. In contrast, simplified 'practical' models are more robust computationally and they can typically be run for thousands of input cases in a matter of minutes. This requires the physical processes that they simulate to be simplified compared with those included in typical research models. The more practical transport models for oscillatory flow above plane beds may be subdivided, following DohmenJanssen (1999), into:

- quasi-steady models based on the assumption that the instantaneous sand transport rate within the wave cycle is proportional to some power of the instantaneous near-bed orbital velocity or bed-shear stress (Madsen and Grant 1976; Van Rijn 1993; Ribberink 1998 for bed load; Bagnold 1966; Bailard 1981; Bailard and Inman 1981 for combined bed and suspended load).

- semi-unsteady models based on the quasi-steady approach, but with a correction factor to represent phase lag effects between the velocity and concentration fields (Dibajnia and Watanabe 1992; Dohmen-Janssen 1999). Dohmen-Janssen (1999) showed that net transport rates in combined wave-current flows are reduced considerably by the influence of phase-lags and that, for waves, the well-known model of Dibajnia and
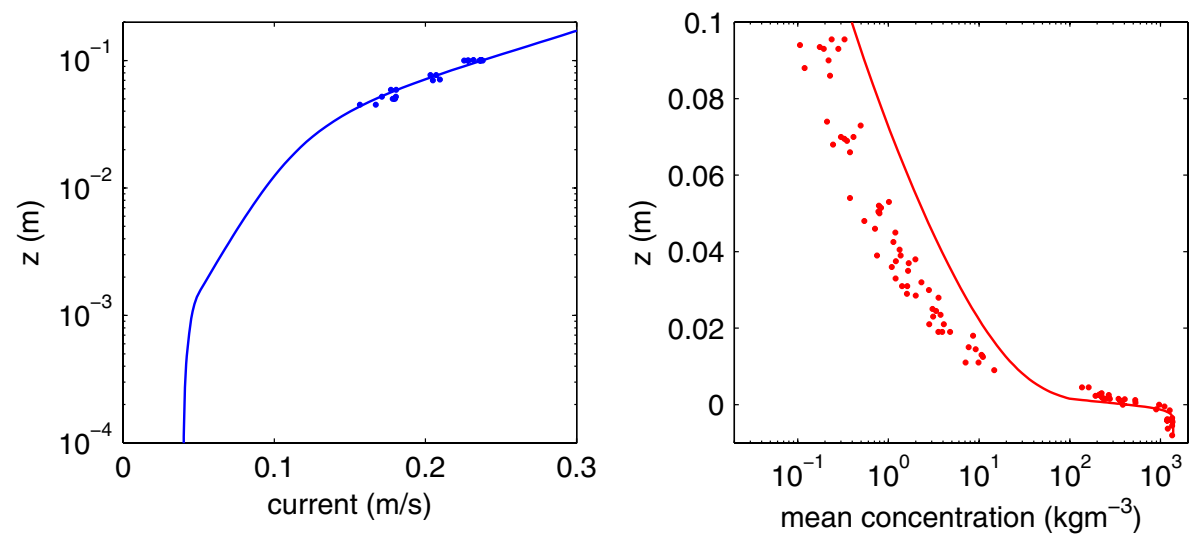

Fig. 6 Sheet flow model of Malarkey et al. (2003) applied to the wave + current data (Test E2) of Dohmen-Janssen et al. (2001). The results show time-mean profiles of velocity (left) and mean concentration (right), where $z$ is the height above the undisturbed bed. Symbols show measurements; lines show model. Parameter settings: wave velocity amplitude $U_{0}=1.47 \mathrm{~m} \mathrm{~s}^{-1}$; wave period $T=7.2 \mathrm{~s}$; current velocity at height $z=0.1 \mathrm{~m}$ is $0.24 \mathrm{~m} \mathrm{~s}^{-1}$; sand grain size $D=0.21 \mathrm{~mm}$; corresponding settling velocity $w_{\mathrm{s}}=2.6 \times 10^{-2} \mathrm{~m} \mathrm{~s}^{-1}$ 
Watanabe (1992) typically predicts the net transport to be offshore (i.e. against the wave direction) on this account.

In relation to sand transport prediction within coastal-area morphological models, a range of practical models, including those above, may be implemented. These approaches include the model of Bijker (1992), the model TRANSPOR2004 of Van Rijn (2005), and the model SEDFLUX (Damgaard et al. 1996; Damgaard et al. 2001; Soulsby 1997). Each of these models represents both the bed load and suspended load but, with the exception of TRANSPOR2004, does not include the wave-related component of the transport. The relative performance of these and other models is summarised later. For an updated view of practical transport modelling the reader is referred to the recent works of Van Rijn (2007a, b, c).

In order to illustrate the predictive capability of research models, an example set of total sediment (mass) transport predictions based on the UWB Sand Transport Model (Li and Davies 2001) is shown in Fig. 7. Here the grain size of the bed sediment is $D=0.25 \mathrm{~mm}$ and the water depth is $h=5 \mathrm{~m}$; the bed roughness $k_{\mathrm{s}}$ and the suspended sediment grain size $D_{\mathrm{s}}$ have been predicted for each point plotted using well established procedures (see Davies and Villaret (2003) for details). The black curve labelled 'Current only' shows that transport $\left(Q_{\mathrm{t}}\right)$ commences when the current strength $\left(U_{\mathrm{c}}\right)$ exceeds a threshold value of about $0.30 \mathrm{~m} \mathrm{~s}^{-1}$, and thereafter $Q_{\mathrm{t}}$ increases by three orders of magnitude as the current strength grows to $U_{\mathrm{c}}=2 \mathrm{~m} \mathrm{~s}^{-1}$. When waves are added (perpendicularly) to the current, the transport rates increase dramatically, particularly so for smaller values of $U_{\mathrm{c}}$. The respective waves (1-4) have (significant) heights of $H=0.5,1,2$ and $3 \mathrm{~m}$ and (peak) periods of $T=5,6,7$ and $8 \mathrm{~s}$. The unexpected overlapping of some of the transport curves for values of $U_{\mathrm{c}}>1 \mathrm{~m} \mathrm{~s}^{-1}$ is caused by the predicted 'wash out' of ripples by the larger waves. This causes a reduction in $k_{\mathrm{s}}$ and, hence, $Q_{\mathrm{t}}$. In other words, for the same current

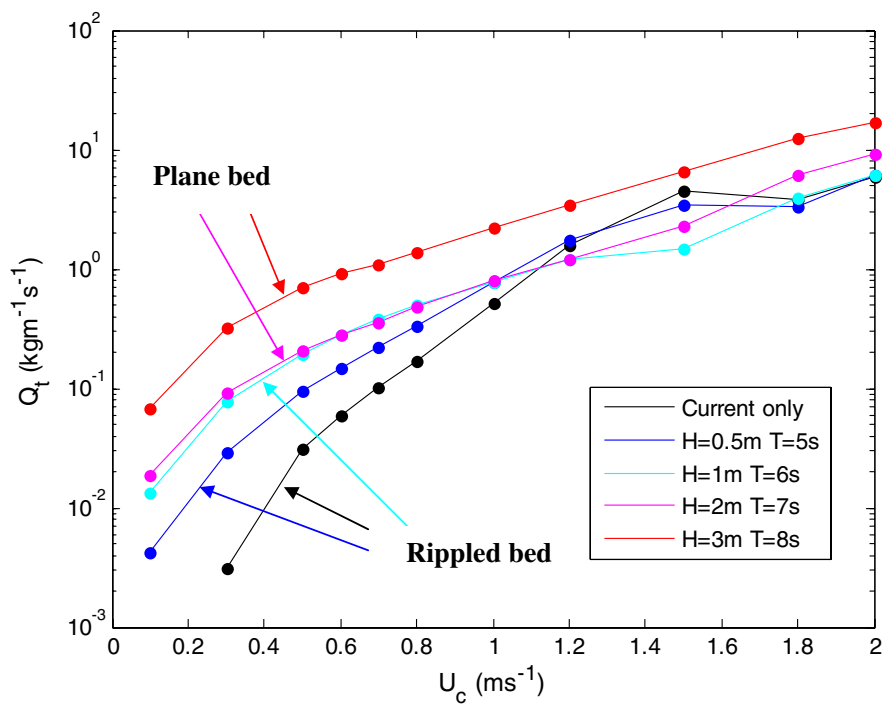

Fig. 7 Results for the total sediment transport rate based on the UWB Sand Transport Model (Davies and $\mathrm{Li}$ 1997) with values of roughness $k_{\mathrm{s}}$ predicted using the procedure of Davies and Villaret (2002). The bedsediment grain size is $D=0.25 \mathrm{~mm}$, and the water depth is $5 \mathrm{~m}$. The black curve refers to a current in isolation, while the coloured curves depict currents combined with waves of differing height and period. Rippled beds are predicted for the three labelled curves, at least up to the point where ripple 'wash-out' occurs (current speed $U_{\mathrm{c}}>1.5 \mathrm{~m} \mathrm{~s}^{-1}$ ) 
strength, lower transport rates are predicted to result from an increase in wave height. As noted earlier, this is indicative of the transport phenomenon being to some extent 'selfregulating' through the process of ripple formation and 'wash out'. The results in Fig. 7 have the same general behaviour as those produced by other practical and research models; for example, Davies and Villaret (2003) showed that qualitatively similar results to those in Fig. 7 are given by the practical model of Bijker (1992) when this latter model is implemented with the same prediction scheme for the bed roughness $\left(k_{\mathrm{s}}\right)$.

\subsection{Rippled Bed Phenomena and Modelling}

As noted in Section 2, sediment transport above rippled beds involves a more complex set of physical phenomena than occurs above plane beds. Reviews concerning sand concentrations and sand transport in oscillatory flow above rippled beds have been provided by Fredsøe and Deigaard (1992); Nielsen (1992); Van Rijn (1993). The oscillatory flow above steep ripples is characterised by the generation, advection and diffusion of near-bed vortices (see Fig. 3) which dictate the behaviour of the suspended sediment grains. Since detailed, intra-wave, field data on sand transport in the rippled bed regime remains scarce, much of our knowledge has been based hitherto on small-scale laboratory studies. The basic characteristics of instantaneous, local sand concentration over ripple profiles have been demonstrated in the laboratory by Bosman (1982); Block et al. (1994); Villard and Osborne (2002) and in the field by Vincent et al. (1999), among others. However, it is only comparatively recently that measuring techniques have become available to properly quantify the process of vortex formation and shedding (e.g. Particle Image Velocimetry (PIV) used in the laboratory by Ahmed and Sato (2001)). In larger scale experiments, acoustic probes have been used to measure the instantaneous concentration and velocity components beneath regular and irregular waves above rippled beds (Chung and Van Rijn 2003), and high-resolution acoustic backscatter systems (ABS) have been used, for example, beneath wave groups to study time-variations in concentration above ripples on longer group-scales (Vincent and Hanes 2002). Thorne et al. (2002a, b, 2003a, b) have reported the results of acoustic backscatter system (ABS) measurements made in a largescale flume, some examples of which are presented in Sect. 4.

In the recent EU project 'SandPit' (2002-2005) (Van Rijn et al. 2005) new research was carried out on sand transport processes mainly in the rippled bed regime. This was because sand transport offshore, particularly in the vicinity of sand pits and trenches, occurs for the most part above rippled beds, even in moderate wave-current conditions. Also, transport in the rippled regime is far less well understood than that in the plane bed regime, particularly at field scales where 'history effects' in the bed forms following, for example, storm events can greatly complicate the situation and can give rise to gross errors in computations (Soulsby and Whitehouse 2005).

In wave-dominated environments, the direction of the net (mainly 'wave-related') transport rate by asymmetric waves over ripples is determined by the ratio of the amount of bed load and suspended load transport (c.f. Fig. 5). If the sediment is transported mainly as bed load, the net transport is likely to be positive ('onshore') due to wave asymmetry. However, if suspended sediment transport is dominant, the net transport rate will be negative ('offshore') due to phase lags between the flow and concentration induced by the lee-vortices in combination with wave asymmetry. These considerations are similar, therefore, to those discussed earlier for plane beds in relation to the model of Dibajnia and Watanabe (1992).

Unsteady modelling of suspended sediment transport above a sand bed covered with (long-crested) ripples requires the simultaneous (numerical) solution of the time-dependent 
momentum equation for the oscillatory fluid flow and the advection-diffusion equation for suspended sediment in the horizontal-vertical (2DHV) plane. The advection-diffusion equation is written:

$$
\frac{\partial C}{\partial t}+\frac{\partial}{\partial x}\left(U C-\varepsilon_{\mathrm{s}, x} \frac{\partial C}{\partial x}\right)+\frac{\partial}{\partial z}\left(\left(W-w_{\mathrm{s}}\right) C-\varepsilon_{\mathrm{s}, z} \frac{\partial C}{\partial z}\right)=0
$$

where $C$ is the instantaneous sand concentration; $U$ and $W$ are the horizontal and vertical instantaneous fluid velocity components; $w_{\mathrm{s}}$ is the settling velocity; $\varepsilon_{\mathrm{s}, x}$ and $\varepsilon_{\mathrm{s}, z}$ are the sediment mixing coefficients in the horizontal $x$ - and vertical $z$-directions; and $t$ is the time. The above equation is more complicated than Eq. 3.1 by the inclusion of advective and diffusive terms in the x-direction and also by the appearance of the velocity components $U$ and $W$ in the respective advective terms. The instantaneous fluid flow and suspended transport in combined wave-current flow over a rippled bed can be solved in an integrated way, which is the great benefit of this approach. However, a major drawback is the relatively large computation time involved; this makes existing 2D (or 3D) rippled bed models entirely unsuitable for application in numerical morphological modelling systems, just as was the case with the plane-bed research models discussed in Section 3.1.

For beds that are steeply rippled, several 2DHV modelling studies have sought to represent the formation and shedding of vortices, and the subsequent trajectories of the (decaying) vortices. For example, Hansen et al. (1994) and Malarkey and Davies (2002) have developed numerical cloud-in-cell (CIC) discrete vortex models. Typical vorticity contours predicted by the latter model at different phase instants beneath a regular symmetric wave are shown in Fig. 8. Such contours give a good visual impression of the scale and sense of rotation of a coherent (vortex) motion. In Fig. 8, a counter-clockwise vortex $(E)$ is located above the ripple lee (left) slope at the instant of flow reversal at phase angle $-90^{\circ}$; this is ejected above the crest following flow reversal $\left(-45^{\circ}\right)$; meanwhile a new vortex $(G)$ forms above the ripple lee slope (now on the right) $\left(-45^{\circ}, 0^{\circ}, 45^{\circ}\right)$, and so on. This sequence is the same as that illustrated in Fig. 3.

Turbulence-closure models have been used above ripples by Perrier (1996), Andersen and Fredsøe (1999) and Andersen et al. (2001). The latter authors noted that the instantaneous stresses over a ripple surface are typically several times larger than on a plane bed, which has important implications for sediment entrainment. At a more fundamental level, Large Eddy Simulation (LES) has started to be used to investigate the importance of coherent flow structures for sediment entrainment above ripples (Zedler and Street 2001). However, despite the development of such models, our knowledge remains fragmentary, not least because the models have been applied in rather limited parameter ranges, typically for which detailed experimental data exists. Nevertheless, several models have succeeded in simulating the vortex shedding process in oscillatory flow convincingly (e.g. Block et al. 1994).

As far as sediment in suspension above ripples is concerned, Lagrangian particle tracking has been used in several oscillatory flow models (e.g. Hansen et al. 1994; Block et al. 1994; Perrier 1996) and, more recently, the model of Magar and Davies (2005) has been used to elucidate the relationship between $v_{\mathrm{t}}$ and $\varepsilon_{\mathrm{s}}$. The process of sediment entrainment above ripples is illustrated using this model in Fig. 9, which shows particles being trapped by a vortex above the lee (left) slope of a ripple. The corresponding instantaneous vorticity contours are shown in the upper part of the figure (c.f. Fig. 8). As time advances, the sediment-laden vortex is ejected (to the right) above the crest (not shown). At the same time, a new vortex starts to form above the lee of the ripple (now on the right), and so on (c.f. Fig. 3). The convective processes acting in this way have been 

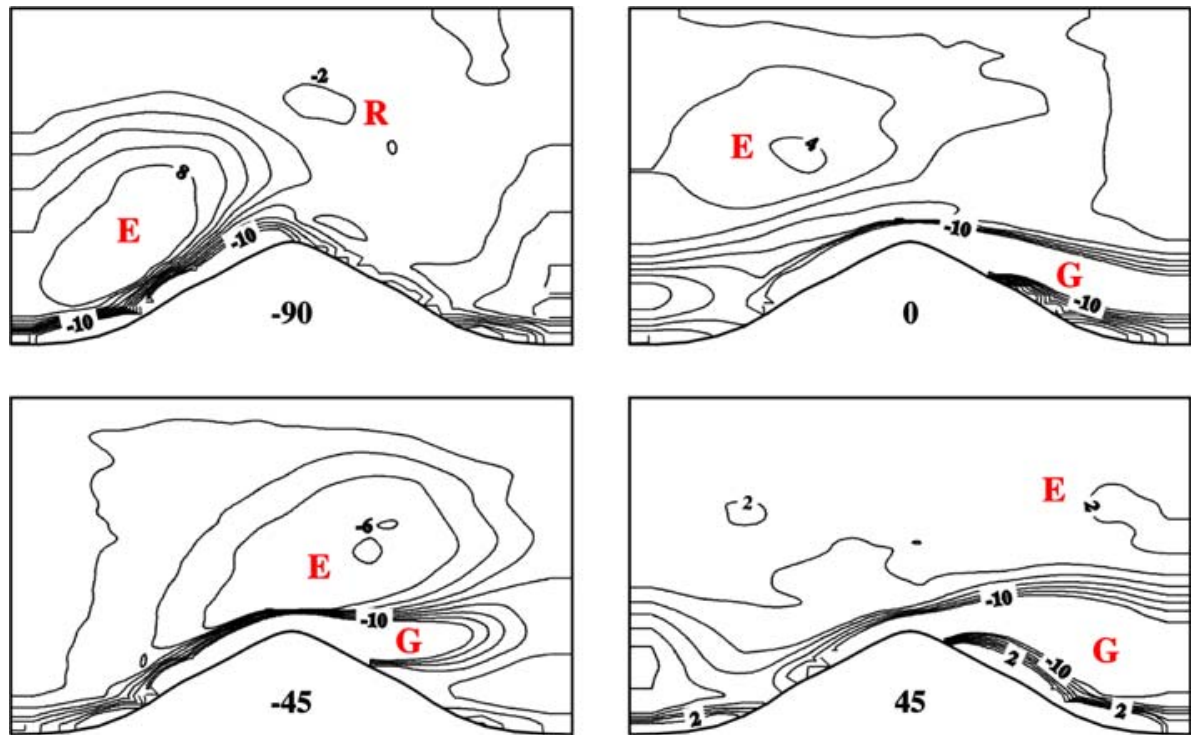

Fig. 8 Vorticity contours above a steeply rippled bed predicted by the discrete-vortex model of Malarkey and Davies (2002). The sinusoidal free-stream velocity is defined by $U_{0} \cos \omega \mathrm{t}$; the large bold numbers indicate the phase angle in degrees and the small numbers indicate the vorticity. The parameter settings are: $A_{0} / \lambda=0.8, T=2.4 \mathrm{~s}, \eta / \lambda=0.18$ with $\lambda=0.10 \mathrm{~m}$. ' $G$ ' denotes the growing vortex, ' $E$ ' the ejected vortex, and ' $R$ ' a relict vortex left from the previous half cycle. Positive vorticity denotes counterclockwise flow

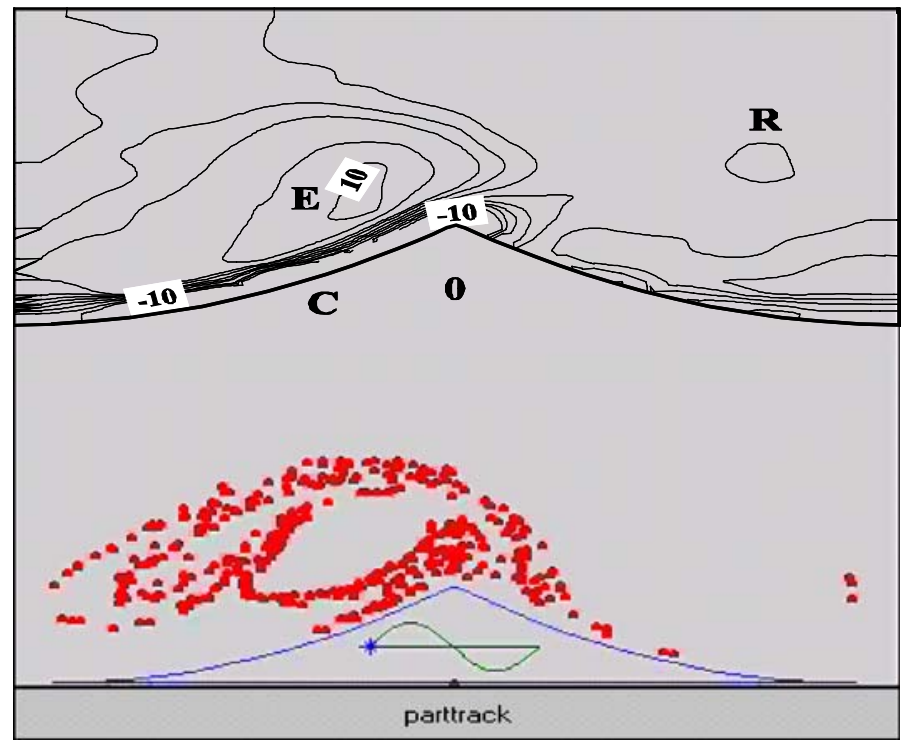

Fig. 9 Vorticity contours and sediment dynamics at the instant of flow reversal, from a discrete-vortex and particle tracking model (Magar and Davies 2005). Each 'particle' shown represents a cluster of individual grains which are advected and diffused in the $2 \mathrm{DHV}$ oscillatory flow $\left(A_{0} / \lambda=1.2\right.$ above ripples of steepness $\eta / \lambda=0.16$ ) 
shown to give rise to values of the quotient $\beta=\varepsilon_{\mathrm{s}} / v_{\mathrm{t}}>1$ that agree well with previous empirical results (e.g. $\beta=4$, Nielsen 1992). The greater efficiency of sediment mixing than the mixing of momentum, implied by this finding, turns out to be a vital process for inclusion in simplified 1DV models (e.g. Davies and Thorne 2005).

Although 2D-models have achieved reasonable success above rippled beds, they are unduly complex and computationally demanding from an engineering point of view. In practice, ripple-scale effects must be parameterized, and this has normally been done using a 1DV approach in which the bed roughness $\left(k_{\mathrm{s}}\right)$ is simply enhanced in an otherwise standard, one-dimensional 'plane bed' formulation in which $v_{\mathrm{t}}$ and $\varepsilon_{\mathrm{s}}$ increase with height above the bed (Nielsen 1992; Chung et al. 2000; Chung and Van Rijn 2003). Far more appropriate (time-mean) formulations for $v_{\mathrm{t}}$ and $\varepsilon_{\mathrm{s}}$ for use above rippled beds have been proposed by Sleath (1991), Nielsen (1992) involving a height-independent eddy viscosity in the near-bed vortex layer. Van Rijn (1993) also found that use of a height-independent sediment diffusivity in the lower layer of a two-layer formulation, in which the diffusivity $\left(\varepsilon_{\mathrm{s}}\right)$ then increases linearly with height, is essential to produce accurate mean concentration profiles above ripples. Subsequently, it was shown by Davies and Villaret $(1997,1999)$ that the time-variation in the eddy viscosity is more pronounced above ripples than above plane beds. Davies and Thorne $(2002,2005)$ developed this approach in modelling sediment transport above ripples, with outcomes that are illustrated in Sect. 4.

Although most simplified 1DV formulations have been based upon classical turbulencediffusion concepts, a rather different argument was developed by Nielsen (1992) involving combined convection and diffusion, the convection aspect here representing the transport of sediment in coherent eddies. In more recent work, Nielsen and Teakle (2004) explored a 'finite mixing length' approach in which the length scale of the turbulent mixing is not strictly "small" compared with the thickness of the boundary layer, as assumed in classical Fickian diffusion.

Some of the more practical, quasi-steady models developed for the wave-related bedload and suspended-load transport in the plane bed regime are commonly used also in the rippled regime, e.g. the Bagnold-Bailard model. However, this type of model generally yields net transport in the forward (onshore) direction (e.g. Houwman and Ruessink 1996), contrary to observation. In contrast, Nielsen (1988) proposed three simple, fairly practical modelling approaches for asymmetrical waves above rippled beds in each of which the net transport is in the 'offshore' direction. He concluded that the validity of quasi-steady models like that of Bailard and Inman (1981) is limited to plane bed conditions. An exception is the model of Sato and Horikawa (1986) which produces net offshore transport beneath asymmetrical waves above ripples.

\subsection{Local Sand Transport Prediction: The State of the Art}

Here we assess how accurate are the individual transport estimates that make up a diagram like that in Fig. 7. The predictive ability of various research and practical sand transport models was assessed by Davies et al. (2002). Initially, seven 'research' models were intercompared over the same wide range of wave and current conditions as in Fig. 7, above a sand bed of given grain size. The models included one-dimensional (1DV) and two-dimensional (2DV) turbulence models and also a two-phase flow formulation, and they were all run with the bed roughness $\left(k_{\mathrm{s}}\right)$ specified. The results of the comparison showed that, in plane bed cases (involving large waves and/or strong currents), the research models agreed within an order of magnitude. However, in cases involving rippled beds (lower waves and weaker currents), the agreement between the models was less convincing, with predicted transport rates differing 
by up to two orders of magnitude in some individual cases. A second intercomparison was carried out between five 'practical' sand transport models. For plane beds the transport rates predicted by the models varied by a factor of between 10 and 30 in the individual cases while, for rippled beds, the variation was in the range 50-200.

A third set of comparisons was carried out between (mainly) practical sand transport models and field data obtained at a variety of sites with differing grain size characteristics. Here the results showed that (mean) suspended sand concentrations in the bottom metre of the flow were predicted within a factor of 2 of the measured values in $13 \%$ to $48 \%$ of the cases considered, and within a factor of 10 in $70 \%$ to $83 \%$ of the cases. There was a tendency for low concentrations to be underpredicted, due probably to a residual amount of suspended sediment being present in quiescent conditions (e.g. near slack water). However, higher concentrations were predicted more convincingly. As far as the prediction of sand transport rates was concerned, the comparisons were more encouraging. Estimates of the longshore (current-related) component of suspended sand transport made by five models yielded agreement within a factor of 2 of the measured values in $22 \%$ to $66 \%$ of cases, and within a factor of 10 in $77 \%$ to $100 \%$ of cases. Vincent and Hanes (2002) pointed out that, in the field, considerable variability (factor of 2 or more) should be expected in the suspended concentration due to 'history effects' in the bed forms, which continually evolve as the waves change their height, period and direction (see Sect. 2).

In the respective comparisons, untuned research and practical models were used. The research models tended to have been validated in laboratory conditions, and then adapted for field use, while the practical models were designed and calibrated for field use. It is not surprising, therefore, that the more sophisticated research models did no better in some of the comparisons than the relatively simple practical methods. It was apparent also that the research models produced results that were more volatile than those from the simpler practical approaches, due in part to the greater sensitivity of the research models to variations in the bed roughness $\left(k_{\mathrm{s}}\right)$.

While the research models were shown in the intercomparisons to be capable of predicting transport rates at field scales as accurately as practical models, Davies et al. (2002) argued that their true benefit lies in the diagnostic analysis that they make possible. The difficulty in implementing research models in, for example, coastal morphological systems, mitigates against their use; the use of more practical models still provides an easier and more robust means of estimating sediment transport rates for this purpose. However it is not only the ability of models to make accurate absolute predictions that is important in sediment transport research. From the point of view of the morphological modeller, what is equally important, and possibly more so, is the relative behaviour of models. In particular, it is important that a transport model shows the correct behaviour (i) as a function of the input parameters (waves, current and grain size) and (ii) over a wide range of conditions involving several orders of magnitude in the transport rate. The correct behaviour of a transport model in this sense is a necessary condition for calibrating a morphological model and obtaining the correct morphodynamic behaviour. Since there was much more agreement in the relative behaviour of the models referred to above than in their ability to produce the same absolute transport rates, the outcome of the comparisons reported by Davies et al. (2002) could be viewed as encouraging from the point of view of morphological modellers.

\section{Observing Sediment Transport}

It may be inferred from the various comments in Sections 2 and 3 that the triad of sediment transport interactions and feedbacks needs to be measured simultaneously, both temporally 
and spatially, in order to understand the fundamental processes of sediment transport. In this section the use of acoustics in visualising how sediments are moved by waves and currents is highlighted.

The concept of using acoustics for underwater sediment transport studies is attractive and straightforward, as illustrated by the diagram in Fig. 10. A pulse of high frequency sound, typically in the range $0.5-5.0 \mathrm{MHz}$ and centimetric in wavelength, is transmitted from a downward pointing directional sound source, usually mounted at about 1 to $2 \mathrm{~m}$ above the bed. The backscattered signal is recorded, typically being gated into range bins of height, say, $1 \mathrm{~cm}$ and then digitised. As the sound pulse travels towards the bed, sediments in suspension backscatter a proportion of the sound, and the bed itself generally returns a stronger echo. The signal backscattered from the suspended particles can provide information on profiles of the suspended sediment concentration, the particle size and the three components of flow velocity, while the bed echo provides the time history of the bed location and, hence, its form if the bed features are moving.

Successive improvements in the understanding of acoustic methodology now allow detailed data to be gathered on the concentration of sediment in suspension, the vertical and horizontal components of the flow, and also the profiles of the ripples on the seabed. Based on a series of transducers and beam scanners deployed above the seabed in the manner illustrated in Fig. 11, the acoustic data can be integrated to generate very detailed, high resolution (about $1 \mathrm{~cm}$ in space and $1 / 10 \mathrm{~s}$ in time) images of sediment transport processes. In practice, acoustics can now measure all three components of the interacting sediment triad (c.f. Fig. 4), and can do this with sufficient spatial and temporal resolution to allow, for example, intra-wave and turbulent processes to be quantified. Importantly, this is done non-intrusively, simultaneously and with the observations co-located (Thorne and

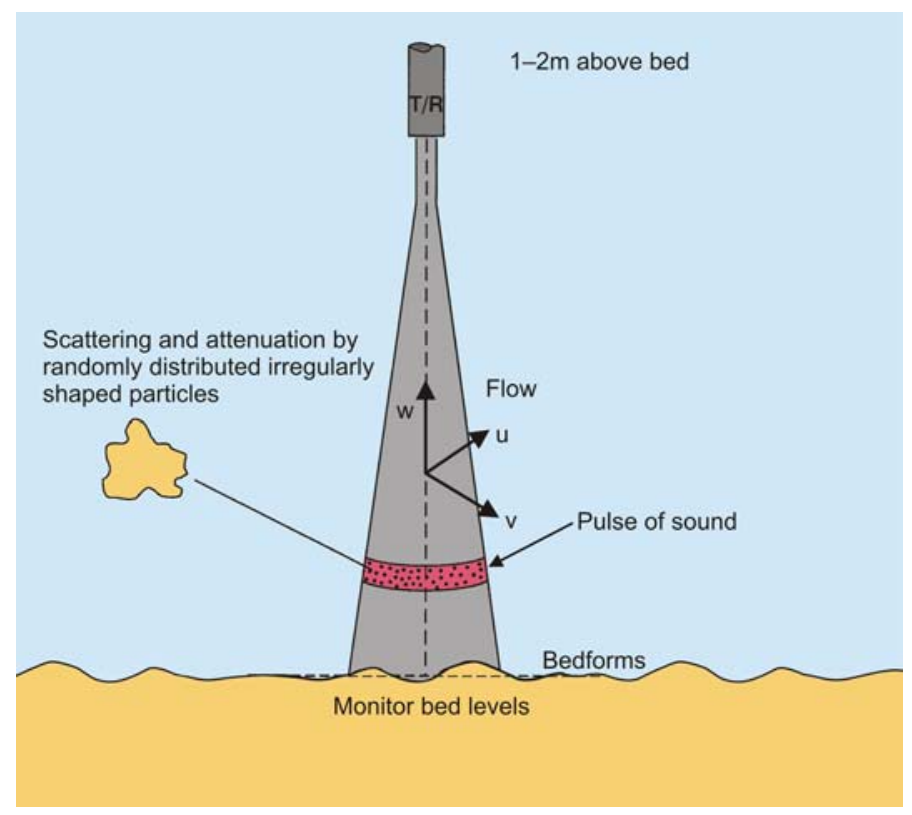

Fig. 10 Diagram outlining the use of acoustics in sediment transport studies. A pulse of high frequency sound is transmitted $(T)$ downwards and the signal backscattered by the suspended particles and the bed is received $(R)$ by the transducer 


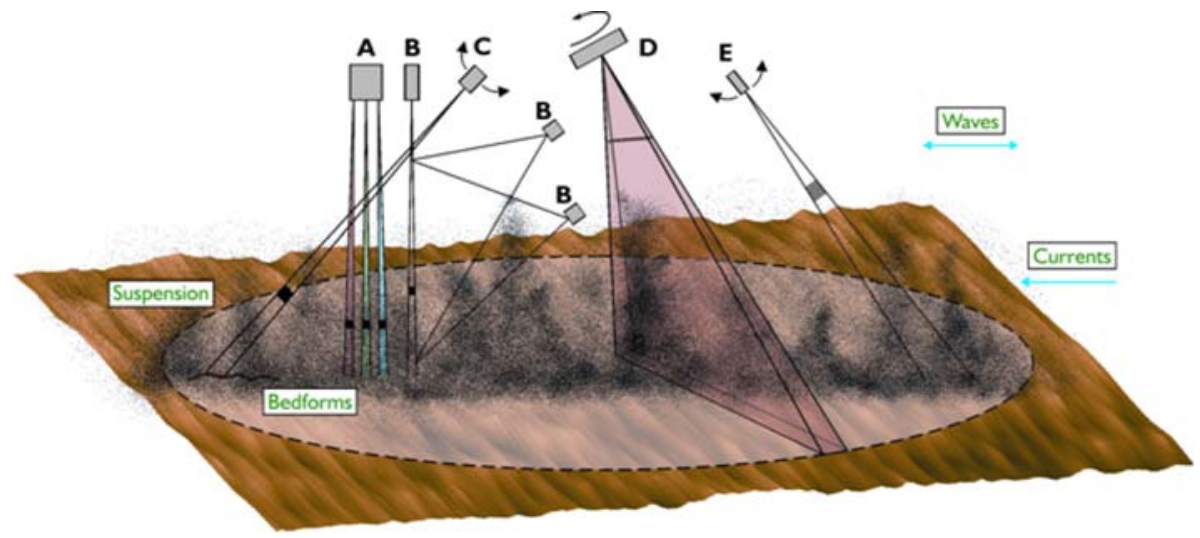

Fig. 11 Schematic of transducers and beam scanners deployed above the seabed in order to monitor nonintrusively the near-bed flow and sediment transport processes. (A) Multifrequency acoustic backscatter for measuring suspended sediment particle size and concentration profiles. (B) Coherent Doppler velocity profiler for measuring the three orthogonal components of flow velocity. (C) Bed ripple profiler for measuring the bed morphology along a transect. (D) High resolution sector scanner for imaging the local bed features. (E) Backscatter scanning system for measuring the relationship between bed form morphology and suspended sediments

Hanes 2002). Such experiments have been carried out in one of the world's largest manmade channels, specifically constructed for wave and sediment transport studies, namely the Deltaflume of WLIDeltares in the Netherlands (Thorne et al. 2002a, b).

The Deltaflume, shown in Fig. 12a, is $230 \mathrm{~m}$ in length, $5 \mathrm{~m}$ in width and $7 \mathrm{~m}$ deep and it allows waves and sediment transport to be studied at full scale. A piston at one end of the flume generates waves that propagate over the bed, before dissipating on a beach at the opposite end. The bed in the experiments reported here comprised medium sand (median diameter $D=0.329 \mathrm{~mm}$ ) which was located approximately halfway along the flume in a
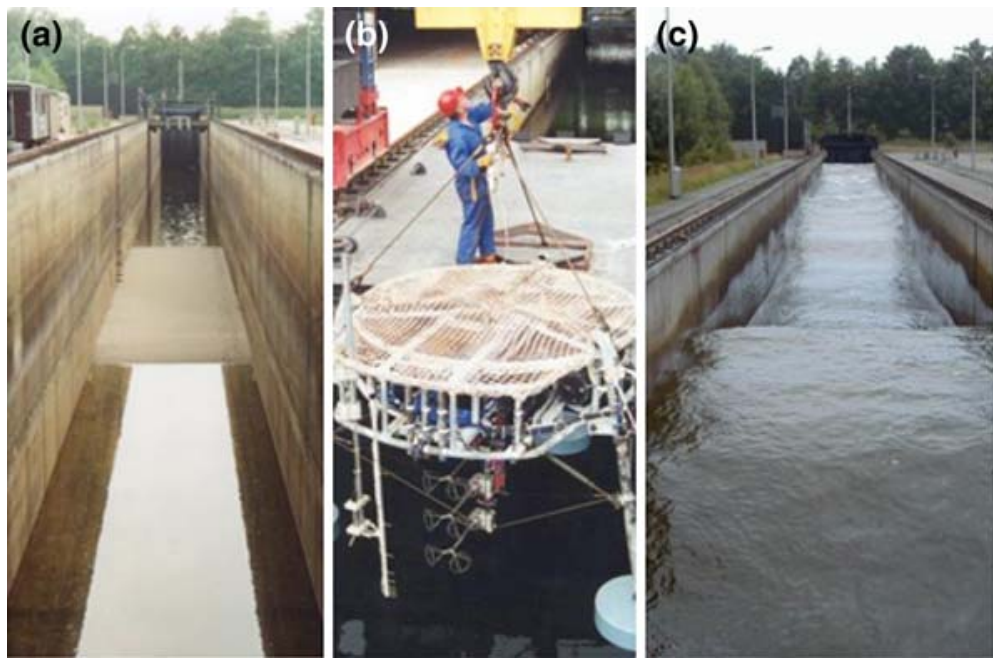

Fig. 12 (a) Photograph of the Deltaflume and the experimental sand patch. (b) The instrumented tripod platform, STABLE II, used to make the acoustic measurements. (c) A wave propagating down the flume 
layer of thickness $0.5 \mathrm{~m}$ and length $30 \mathrm{~m}$. An instrumented tripod platform was developed in order to make the acoustic and other auxiliary measurements (c.f. Fig. 12b). The tripod STABLE II (Sediment Transport And Boundary Layer Equipment) used an acoustic backscatter system (ABS) to measure profiles of particle size and concentration, a pencil beam acoustic ripple profiler (ARP) to measure the bedforms and electromagnetic current meters (ECMs) to measure the horizontal and vertical flow components. Figure 12c shows a wave propagating along the flume while STABLE II was submerged; the water had a depth $4.5 \mathrm{~m}$, which is typical of coastal zone conditions. The experiments were carried out with regular, weakly asymmetric waves having heights $(\mathrm{H})$ and periods $(\mathrm{T})$ in the respective ranges $0.6-1.3 \mathrm{~m}$ and $4-6 \mathrm{~s}$.

To investigate and then model the vortex entrainment process, it was necessary to establish at the outset whether or not the surface waves were generating ripples on the bed. To this end a $3 \mathrm{~m}$ transect of the bed was measured over time using the ARP. The results of the observations over a $90 \mathrm{~min}$ recording period are shown in Fig. 13. Not only were ripples formed on the bed but they were also mobile. Moreover the individual ripple crests remained coherent through the experiment. As noted in Sect. 2, flow separation and hence vortex formation require the ripple steepness $(\eta / \lambda)$ to exceed about 0.12 ; during the present observations $\eta / \lambda$ was approximately 0.14 .

The ABS system was used to capture the associated, time-varying, suspended sediment concentration profiles (Thorne et al. 2003b). The detailed images shown in Fig. 14 were constructed over a $20 \mathrm{~min}$ period as a ripple passed in the onshore direction beneath the ABS. The suspended concentrations at different locations on the ripple, at the same (four) velocity instants during the wave cycle, were combined to generate the respective images. The length and direction of the white arrows in the figure indicates the magnitude and direction of the wave velocity. Comparison of Fig. 14 with Fig. 3 shows close similarities. The development of a high concentration event can be observed in Fig. 14a at high flow velocity above the lee slope of the ripple ( $v_{1}$ in Fig. 3). In Fig. 14b as the forward flow reduces in strength, the near-bed sediment-laden parcel of fluid, now of increased size, travels up the lee side of the ripple towards the crest. As the flow reverses this sediment laden fluid parcel $\left(v_{1}\right)$ travels over the crest and expands further. As the reverse (offshore)

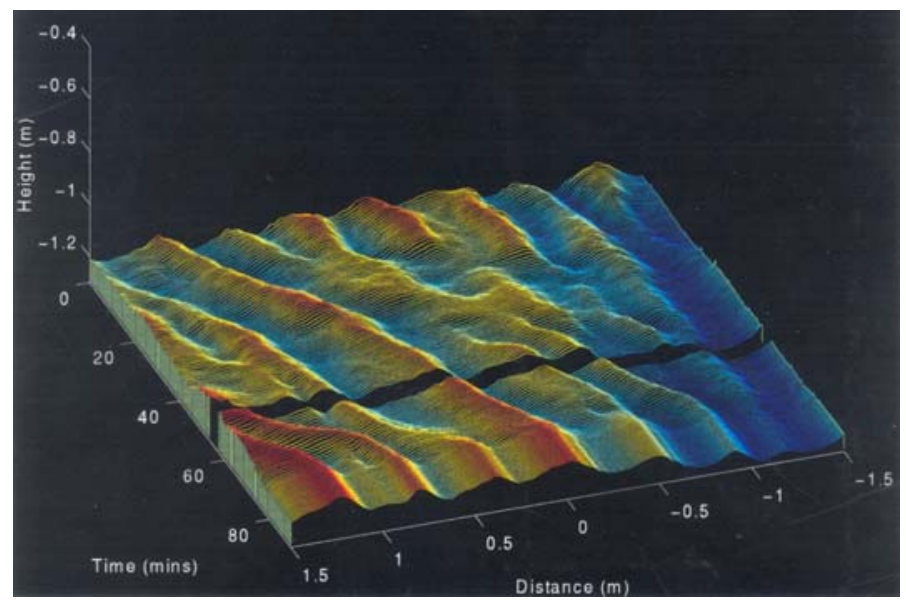

Fig. 13 Ripple profiler (ARP) measurements of sand ripples on the bed during a typical 90 min recording period in the Deltaflume 


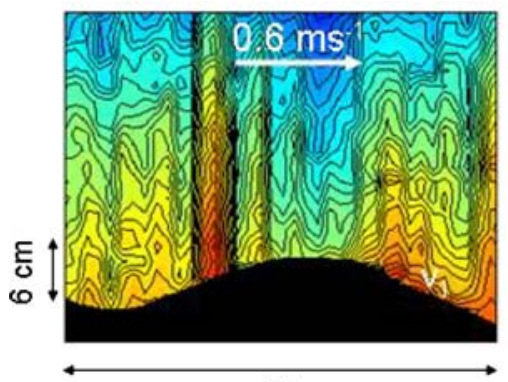

$42 \mathrm{~cm}$

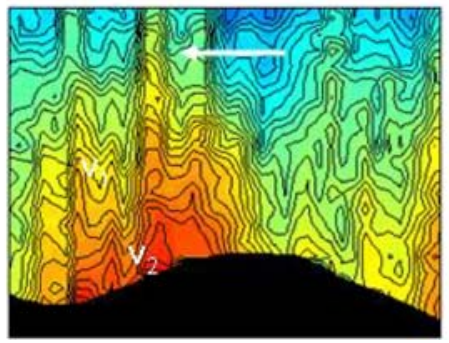

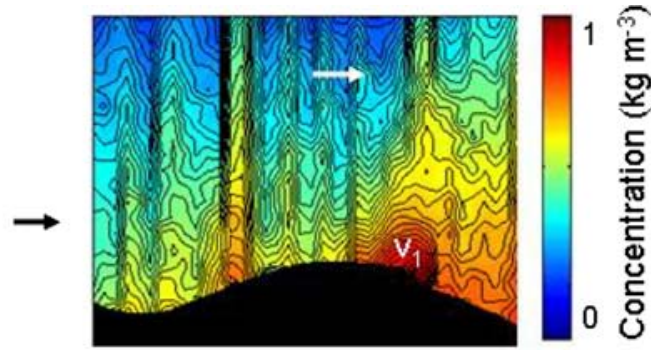
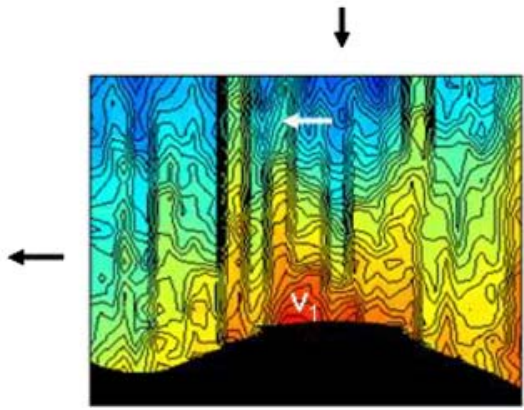

Fig. 14 Sound imaging of vortex suspended sand entrainment over a rippled bed due to surface waves. The white arrows indicate the direction and strength of the free-stream velocity. The vortices $v_{1}$ and $v_{2}$ correspond with those in Fig. 3

flow increases in strength, Fig. 14d, the vortex $v_{1}$ begins to lift away from the bed and a new sediment-laden lee vortex $\left(v_{2}\right)$ is initiated on the opposite slope of the ripple.

In order to capture the essential features of this data within the relatively simple 1DV, UWB Sand Transport Model (Davies and Thorne 2002, 2005), the ABS data was first horizontally averaged over one ripple wavelength at each phase instant during the wave cycle. The resulting pattern of sediment suspension contours is shown in the right panel of Fig. 15, while the upper panel shows the oscillating velocity field measured at a height of $0.3 \mathrm{~m}$ above the bed. The concentration contours shown here are relative to the ripple crest level, the mean (undisturbed) bed level being at height $z=0$, and the ripple height and length were measured by the ARP as $0.06 \mathrm{~m}$ and $0.42 \mathrm{~m}$, respectively.

The measured concentration contours in Fig. 15 show two high concentration peaks near the bed that propagate rapidly upwards to several ripple heights. The first, and stronger, of these peaks occurs slightly ahead of flow reversal, while the second weaker, and more dispersed peak is centred on flow reversal. The difference between the strengths of the two peaks reflects the greater forward velocity that can be seen to occur beneath the wave crest (time $=0 \mathrm{~s})$ than beneath the wave trough $(2.5 \mathrm{~s})$. Between the two concentration peaks the sediment settled rapidly to the bed. Maybe rather unexpectedly this settling effect occurred at the times of strong forward and backward velocity at levels well above the bed. The underlying mechanism of sediment entrainment by vortices shed at or near flow reversal is clearly evident in the spatially-averaged measurements shown in Fig. 15.

As discussed in detail by Eidsvik (2006), any conventional 'plane rough bed' model that attempts to represent the above sequence of events in the suspension layer runs into severe difficulties, since such models predict maximum near-bed concentration at about the time of maximum flow velocity, and not at flow reversal. The UWB Sand Transport Model 

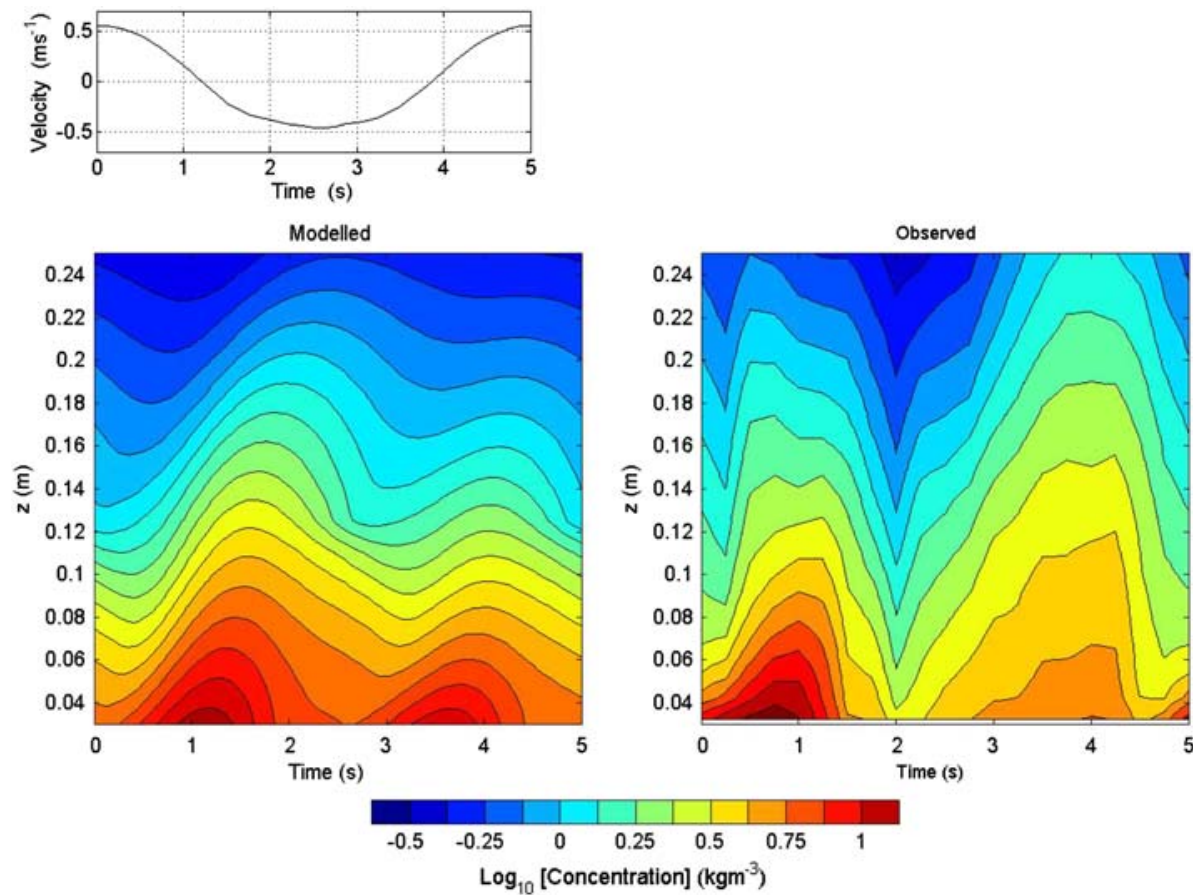

Fig. 15 Modelled (left) and measured (right) suspended sediment concentration during a wave cycle (period $T=5 \mathrm{~s})$. The origin of the height $(z-)$ axis is taken at the mean bed level. The measured free-stream velocity is shown in the upper panel. Parameter settings: wave height $H=1.06 \mathrm{~m}$, wave period $T=5 \mathrm{~s}$, water depth $h=4.5 \mathrm{~m}$

seeks to capture these effects through the use of a strongly time varying eddy viscosity that represents the timing and strength of the upward mixing events due to vortex shedding. The model initially predicts the size of the wave-induced ripples and the size of the grains found in suspension, and then goes on to solve numerically the equations governing the upward diffusion and downward settling of the suspended sediment (see Sect. 3.2). The resulting concentration contours in the present case are shown in the left panel of Fig. 15. These results have been obtained using a sediment settling velocity of $w_{\mathrm{s}}=2.47 \times 10^{-2} \mathrm{~m} \mathrm{~s}^{-1}$, corresponding to the predicted median size of the grains in suspension in this experiment. The essential two-peak structure of the eddy shedding process is represented rather well, with the initial concentration peak being dominant. The decay rate of the concentration peaks as they go upwards is also represented quite well, though a phase lag develops with height that is not seen to the same extent in the data. Nevertheless, despite some discrepancies, the model and experiment are well matched. This suggests that the present model may be used with some confidence in the rippled regime for practical prediction purposes.

\section{Morphological Modelling}

The term 'morphological modelling' represents the attempt to understand and predict both natural developments such as the growth of sand banks, and also the impact of man-made 
developments such as navigation trenches or pits for sand extraction. Will such pits infill/ scour, will they migrate and, importantly, will they affect the nearby coastline adversely? These are the kinds of predictions that are increasingly being made by coastal scientists and engineers. However, whether these predictions are believable, for example by coastal managers, depends upon the validation of the flow and transport modelling locally within the computational domain. This validation has to be done ideally through field measurements on site but, as highlighted earlier, is helped also by the use of large scale laboratory facilities in which sand transport phenomena can be measured at full scale.

A typical morphological computation of a coastal area starts with the present-day bathymetry for which the current regime (e.g. Spring-Neap tidal cycle) and wave field (e.g. based on an annual schematization) are computed. It was noted earlier that significant progress has been made in recent years towards improved local sand transport modelling. Importantly, these local transport models are believed to have the correct general behaviour over the wide range of wave and current conditions encountered on site. For the purposes of morphological modelling in a coastal area the transport formulation applied at each computational point in the domain must also be robust; this means that it must be either of 'practical' type or a simplified parameterisation based on a 'research model'. The chosen formulation must be applicable and sufficiently accurate for the full range of conditions on site. For a typical offshore site in, say, the North Sea, if you ask the question 'What conditions contribute the most to the net annual sediment transport rate?', the answer based on local sand transport modelling is that (Soulsby 1987, 1997):

- while storm events have a major impact, they only occur for a very limited period each year;

- for most of the year waves are actually very low and, at these times, the tidal currents on their own move very little sediment;

- in fact, it is the middle-sized waves combined with middle-sized currents occurring over many weeks each year that have the greatest overall influence on sediment transport pathways.

The same is true also of the nearshore coastal zone (Soulsby and Malarkey 2005). The challenge in morphological modelling is to represent this annual 'texture' in a believable, simplified manner. This is done commonly by employing 'input filtering' whereby the annual wave conditions on site are schematized into a set of events, often quite limited in number, to characterize the annual wave conditions; where tides are concerned a 'morphological tide' is usually defined (Van Rijn et al. 2005; Chesher et al. 2005). The wave modules used in existing morphological models tend to predict the way in which a spectrum of waves evolves on entering shallow, and then shoaling, water, but they do not describe the intra-wave hydrodynamics and sediment transport. New Boussinesq-type intra-wave models, and also 'saw-tooth' wave models (Van Rijn et al. 2007a), linked to simplified sediment transport formulations, are now starting to be developed for use in coastal-area modelling. However at the present stage of this research, hydrodynamic issues can still introduce major uncertainty into nearshore morphological model predictions. For example, rather crude and sometimes inappropriate surf zone formulations (e.g. neglecting undertow) are commonly applied to determine, for example, the bottom wave-induced velocities used in sediment transport computations.

The combined effects of the waves and currents on the seabed sediments having been estimated, sediment transport divergences are determined in order to establish areas of net sediment accretion and erosion. The computed seabed bathymetry is thereby updated repeatedly during a morphological simulation which may be of duration months or even 
years. A typical 'morphological loop' is shown in Fig. 16. The updated bathymetry changes the (tidal) currents and the waves, which are recalculated for the period following, leading to further updating of the bathymetry, and so on and on. The aim of this exercise is to project the bathymetry into the future using an essentially deterministic approach, but subject to some inherent uncertainty arising from the (usually) simplified model inputs (tides, waves, sediments).

Since the predictions of local sand transport models are required as input for morphodynamic models, the quality of a morphodynamic model clearly depends upon the quality of the underlying sediment transport model. Davies et al. (2002) concluded that, if a user selects a research or practical model randomly 'off the shelf', and then uses it in an 'untuned' manner to make predictions for field conditions, considerable uncertainty should be expected. Despite the recent model improvements reported by Van Rijn et al. (2005) (see also Van Rijn et al. 2007b), the state-of-the-art in sand transport research still requires some knowledge of conditions on site, allowing the user to carry out model validation and/ or tuning and, hence, make an informed judgement about the optimum choice of model for use in sand transport computations. Van Rijn et al. (2005) pointed out that in many previous validation studies there had been a tendency to focus only on, e.g., the back filling of trenches and sand pits, without information being provided on the reliability of the sediment predictors used in the simulations. This problem was recognised and addressed by Walstra et al. (2005) who argued that the modelling approach itself (e.g. coupling of wave and flow models, and up-scaling of the simulated morphology) was an important aspect in helping to explain the differences between model outcomes.

The intercomparison of several morphological models presented by Walstra et al. (2005) was mainly with reference to trench-infill cases for which validation data was available. This study showed that the differences between the various model predictions of morphological change were relatively large. This was considered particularly surprising since, in some cases, identical flow models were used with similar parameter settings and similar transport formulations. Subtle differences in how the models were calibrated and implemented evidently led to a relative large amount of variability in the morphological predictions. More work remains to be done on the implementation of local sand transport

Fig. 16 Model template showing the basic modules comprising a possible 'morphological loop'. FW: the flow computation is run and fed to the wave module. WF: waves and currents are fed into the flow model to calculate wave-induced currents. FT: the wave + current flow is fed into the sediment transport module. TB: transport divergences are used to compute the bed change. BF: the updated bottom bathymetry is fed back into the flow module, which is then re-run. The loop then repeats

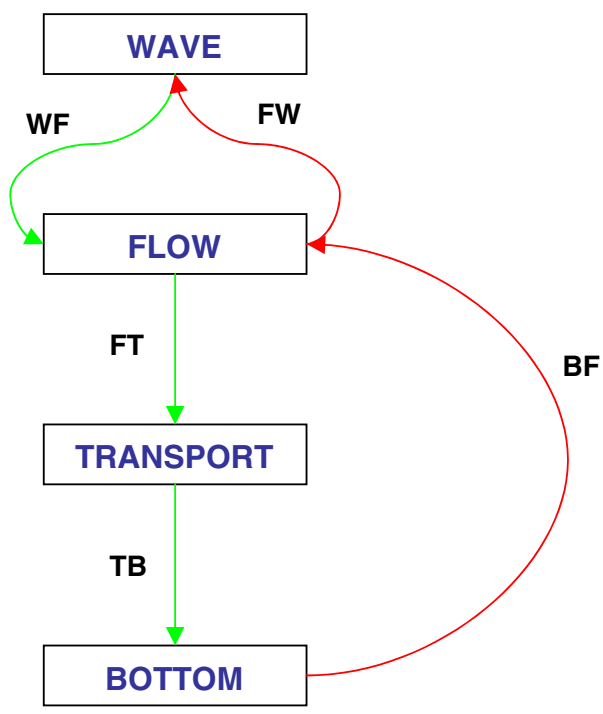


modelling concepts within practical transport formulations leading, hopefully, to improved morphological outcomes.

Even if a local sand transport model is highly accurate, it does not necessarily follow that correct predictions will result from its use in a coastal morphological scheme. Horizontal advection-diffusion effects on the suspended sand transport, which are not included in local transport modelling (and which occur effectively at sub-grid scales in the morphological scheme), need to be taken into account. Throughout a morphological simulation the changes in the seabed elevation are predicted via a bed continuity equation (Fredsøe and Deigaard 1992), a simple example of which in 2D is:

$$
(1-n) \frac{\partial Z_{\mathrm{f}}}{\partial t}+\operatorname{div}\left(\underline{q_{\mathrm{t}}}\right)=0
$$

where $Z_{\mathrm{f}}$ is the bed elevation, $\mathrm{n}$ is the porosity, and $q_{\mathrm{t}}$ is the (total) sand transport rate vector. Through the divergence operator, any net accumulation/removal of sediment within a computational cell results in an increase/decrease in the elevation of the bed in that cell. The degree of sophistication with which the sediment transport $q_{\mathrm{t}}$ is predicted is the key to success here; for example, an appropriate method must be used to represent bed slope effects. The simplest approach for bed updating is to use a 'local equilibrium' formulation (Eq. 5.1) in which all of the sediment (bed load and suspended load) entering/leaving a computational cell is assumed to result in changes in bed elevation. However, this approach tends to exaggerate bed changes since, in reality, the suspended load may remain largely 'in the flow' not interacting with the bed. Thus, more sophisticated, and physically more correct, formulations (Soulsby 1997) are continually being sought to represent the suspended load, for example through advection-diffusion schemes in which the depthintegrated equation for suspended sediment transport is written:

$$
\frac{\partial C}{\partial t}+U \frac{\partial C}{\partial x}+V \frac{\partial C}{\partial y}=\frac{1}{h}\left[\frac{\partial}{\partial x}\left(h \varepsilon_{\mathrm{s}} \frac{\partial C}{\partial x}\right)+\frac{\partial}{\partial y}\left(h \varepsilon_{\mathrm{s}} \frac{\partial C}{\partial y}\right)\right]+\frac{(E-D)_{z=a}}{h}
$$

where $h=$ water depth, $(U, V)=$ depth-averaged flow velocities in $(x, y)$ directions, $\varepsilon_{\mathrm{s}}=$ sediment diffusivity, $(E-D)=$ erosion minus deposition flux of sediment at the interface $(z=a)$ between the suspended-load layer and the bed-load layer. The earlier 'equilibrium' bottom-evolution equation (5.1) is then elaborated to include vertical fluxes at, typically, $z=a=\max \left(2 D_{50}, k_{\mathrm{s}}\right)$, as follows:

$$
(1-n) \frac{\partial Z_{\mathrm{f}}}{\partial t}+\operatorname{div}\left(\underline{q_{\mathrm{b}}}\right)+(E-D)_{z=a}=0
$$

where $q_{\mathrm{b}}=$ bed-load transport rate. The erosion and deposition fluxes may be written most simply:

$$
(E-D)_{z=a}=w_{\mathrm{s}}\left(C_{\mathrm{eq}}-C_{z=a}\right)
$$

where $w_{\mathrm{s}}$ is the settling velocity, $C_{\mathrm{eq}}$ is the 'equilibrium' concentration at $z=a$ expected from consideration of the local bed shear stress, while $C_{z=a}$ is the actual concentration inferred from the upstream suspended sediment flux. The use of these equations separates the interaction with the seabed of the bed load (represented by the divergence term in Eq. 5.3) and the suspended load (represented by the erosion/deposition term). The treatment of the deposition term $(D)$ may be further elaborated in 2DH modelling through the use of 'lag functions' (Miles 1986; Wang and Ribberink 1986). 
These principles have been used within the TELEMAC Modelling System (Hervouet and Bates 2000) by Davies et al. (2005) where, additionally, a new prediction scheme was introduced for the determination of the local bed roughness $\left(k_{\mathrm{s}}\right)$. Davies and Villaret (2003) had earlier shown that the morphological modelling of seabed topography may be influenced significantly by spatial variations in the bed roughness and that, despite the possibility of bed/numerical instability if this effect is included, morphological models should, in principle, incorporate this potentially important feature. Although the bed roughness is one of the most important, and also uncertain, parameters with regard to morphological modelling, very few models include a local roughness predictor. Present day models are distinguished from one another mainly through the concepts used to simulate the hydrodynamics (2DH or 3D modelling) and also their inclusion, or otherwise, of 'lag effects' to simulate the suspended sediment load.

As an illustrative example of the morphological changes that can be predicted in the coastal zone, we conclude with the case of the Dyfi Estuary, mid-Wales, U.K., where a TELEMAC simulation has been carried out (see Davies and Brown 2007; Brown and Davies 2007). The Dyfi is a sandy estuary subject to tidal currents combined with waves mainly from the south-west direction. The model domain and bathymetry are shown in Fig. 17. The estuary comprises extensive sand flats and some discrete channels, in contrast with the rather deeper water in the offshore area. The predicted tidal currents offshore are low $\left(<0.3 \mathrm{~m} \mathrm{~s}^{-1}\right)$ and hardly capable of moving sediment. However in the main entry channel to the estuary current strengths can exceed $1.5 \mathrm{~m} / \mathrm{s}$ giving rise to very active transport conditions. A key feature of the modelled transport arises from wave-generated longshore currents that can achieve values of, typically, $0.75 \mathrm{~m} \mathrm{~s}^{-1}$ in shallow water in the nearshore zone. The resulting littoral drift, which is normally in the northward direction, contributes a significant sediment flux that may enter the estuary, or may become trapped at the estuary mouth, or may proceed northward up the coast. In order to represent this complex coastal system within TELEMAC, over an annual cycle, the observed climate of waves was broken down into 32 wave events which were then combined with the tides in order to make a sequence of sediment transport predictions, at half hourly intervals, through the course of 1 year. These local transport predictions were based on a parameterised version of the UWB Sand Transport Model (c.f. Fig. 7).

The cumulative effect of convergences and divergences in the predicted sediment transport rates is to produce seabed morphological change. The results in Fig. 18 show this change at the estuary mouth. Here the initial bathymetry is indicated by the black contour lines, and the final bathymetry after 371 days is represented by the superimposed colour map. The two patterns are somewhat different, revealing both areas of predicted bank evolution and also a lengthening of the main channel leading into the estuary. A scour pit at the eastern end of this entry channel is predicted to remain as a stable feature of the system after 1 year, neither deepening nor infilling (Davies and Brown 2007). The pattern of black dashed lines/arrows shows the net transport of sediment due mainly to the littoral drift arising from the predominant wave action from the south west. This sediment entering the estuary mouth behaves as outlined above, contributing to the pattern of morphological change as it passes through the area. Brown and Davies (2007) suggested that, due to ebbdominance in the tidal flow, the inner Dyfi Estuary is presently exporting sediment towards its mouth and offshore area. More generally, while the predicted morphological changes in Fig. 18 are significant and interesting, they need to be tested critically in comparison with high quality observations which here, and in most other morphological applications, are unavailable. Nevertheless, the present example shows the nature and present capability of morphological modelling systems. 


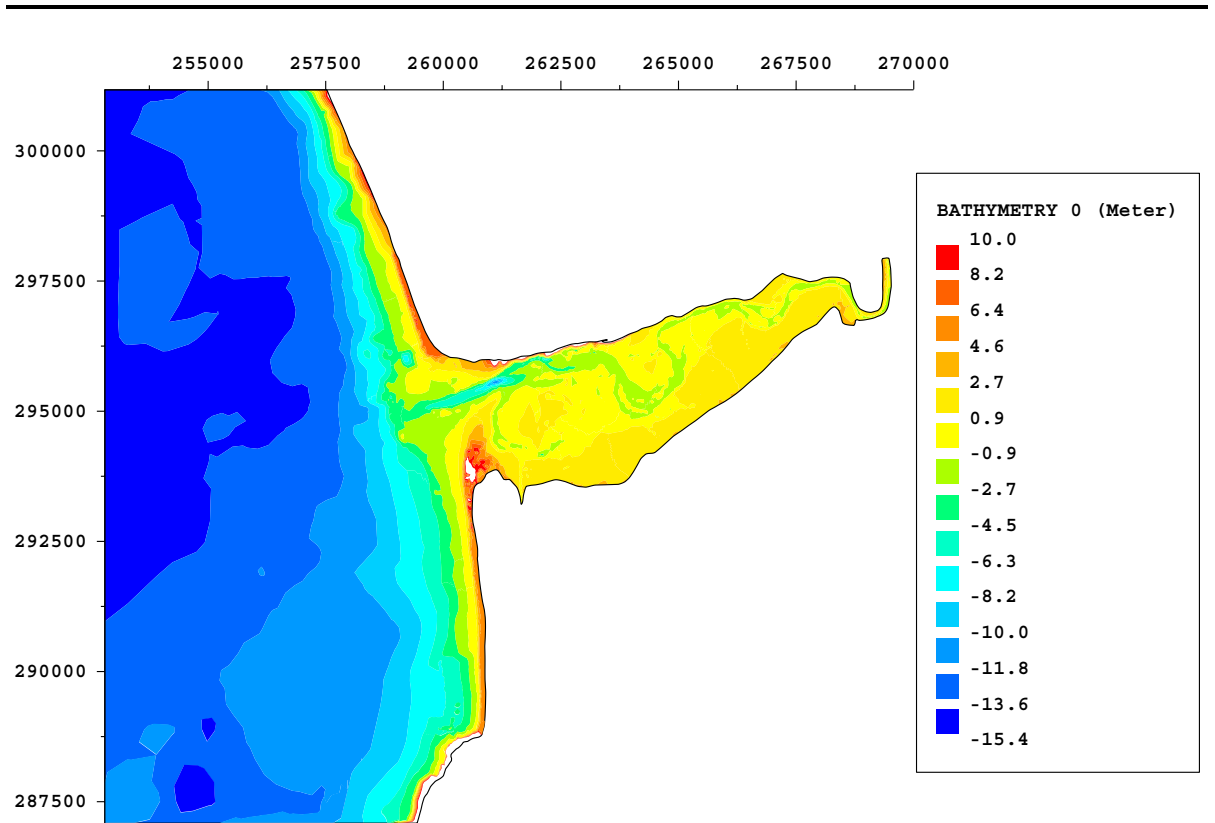

Fig. 17 The domain and bathymetry of the Telemac model of the Dyfi Estuary, mid- Wales (Davies and Brown 2007). The domain extends approximately $15 \mathrm{~km}$ in both the North-South and East-West directions. The depths in the colour bar are with reference to Ordnance Datum

\section{Discussion and Future Perspectives}

Long gone are the days when coastal sediment transport predictions were commonly in error by orders of magnitude. Although this is not appreciated by some casual observers of the field, dramatic advances have been made in the last 10-20 years, particularly for noncohesive sediments (sands). The key to successful bed friction and, hence, sediment transport prediction remains our ability to estimate the roughness of the seabed which depends, in turn, upon the heights and wavelengths of the ripples formed by the waves and currents. Although many uncertainties still remain, particularly for natural mixtures of sediment sizes, we are now much more confident about predicting both the roughness of the bed, and also the associated and often complex mixing processes above the bed, than was the case 20 years ago. Our understanding of the complete sediment 'triad' (Fig. 4) can now be considered quite well advanced. In practice, net sediment transport predictions in 'blind' field tests can often be validated to within a factor of \pm 2 in individual cases, which represents an enormous improvement on past uncertainties. In fact, our most recent validated models can be expected to give more or less the correct result on average, which represents a good achievement given the uncertainties about the various inputs to the models. Also importantly, the new generation of local transport models is believed to have the correct general behaviour over the wide range of wave, current and sediment conditions found in typical coastal areas, which is a prerequisite for successful morphological modelling.

At the present stage of this research, it is probably correct to say that many of the advances that have been made in local sand transport modelling have not yet been implemented fully, or even partially, into coastal sand transport and morphological models. Although the new generation of morphological models operates at a very high level with regard to the 


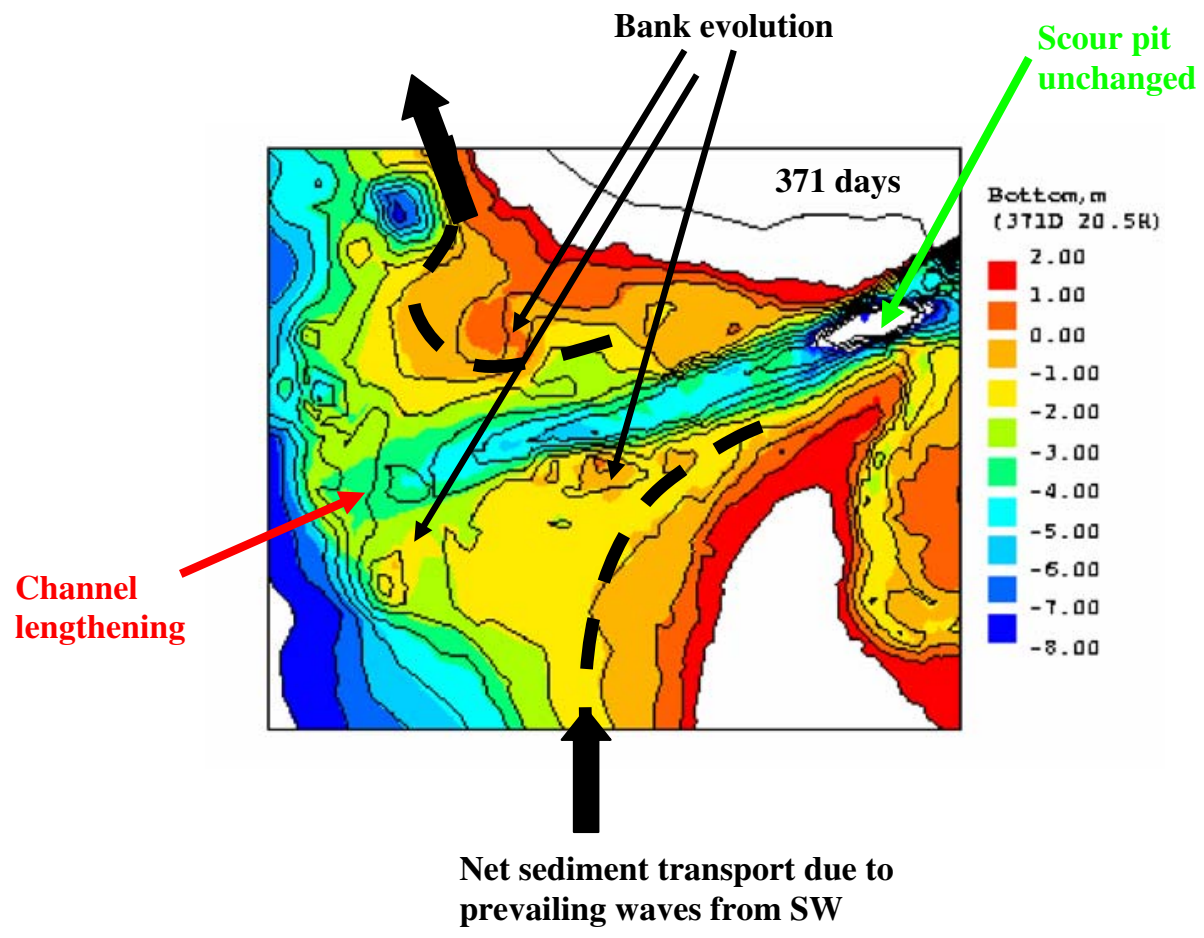

Fig. 18 Morphological prediction of the change in the bathymetry at the mouth of the Dyfi Estuary after 1 year (371 days). The original bathymetry is shown by the full black lines and the new bathymetry by the colour map. The differences highlighted are discussed in the accompanying text. The pattern of black dashed lines/arrows shows the net sediment transport pathways

prediction of tidal currents and waves, the models are still too simplistic in their representation of wave-current interaction, wave-induced currents and small-scale sediment transport processes. This is a gap that the present authors, among others, are trying to fill by producing improved parameterisations that capture the essential physics of sediment transport within a formulation that is both realistic, and also sufficiently simple and robust to be implemented in an area model. Added to this is the need to develop better methods of schematising the annual climate of waves and also the tidal currents present on site.

At a technical level, particularly relating to acoustics, substantial progress has already been made, though there is still much potential to realise. At present a number of acoustic instruments separately collect the different measurements, and an important aim is now to try to integrate these systems. In addition, higher spatial and temporal resolution is required near the water-seabed interface in order to probe further this high-concentration region where most sediment transport occurs. In the future, other measurement techniques might come into play. For example, laser technologies have been implemented recently that can also can supply information on the suspended sediments.

Regarding climate change, rising sea-levels and increased storminess, the challenge for the future is to determine how the seabed will respond on a decadal basis to increased sea level. In the UK context, present estimates of the likely impact of global sea-level rise differ substantially from one another; a conservative estimate would perhaps be about $2 \mathrm{~mm} /$ year, divided roughly equally between ice melt and the thermal expansion of sea 
water. In the south-east of the UK the additional effect of the Earth's crustal movement consequent upon the last ice age (Shennan 1989) is effectively doubling the rate of sea level rise to about $4 \mathrm{~mm} /$ year.

While this rate of change of sea-level is rapid, it is not the only aspect of climate change that must be taken into account. There has been observational evidence of increasing wave height in the North Atlantic over the last quarter-century, linked partly to the North Atlantic Oscillation (Wolf and Woolf 2006). Particularly important for coastal defence is the conclusion of Wolf and Woolf (2006), based on model studies, that the maximum wave height is affected significantly by the intensity, track and speed of storms across the Atlantic. Increased storminess in the future will give rise not only to increased wave height but may, in turn, be accompanied by higher storm surge levels. It is the combined effect of sea level rise, increased storminess and increased surge level that may cause substantial changes to the coastline in the future.

As noted by Wolf and Woolf (2005) the most important issue for individuals and communities faced with management decisions related to climate change is the likely local impact, since there may be large local variations (e.g. in wave height, rainfall, etc.) in relation to the global/regional average. Zones of present-day sediment accretion/accumulation may in the future become zones of net erosion requiring new management strategies; this may occur, for example, in estuaries (Brown and Davies 2007). Man appears to have already accelerated global climate change, leading to sea level rise. Our potential response is likely to include the nourishing of beaches and the building of tidal barrages, both of which may alter regional sedimentation patterns.

Many challenges remain for the future in sediment transport research. What happens to our 'clean sand' predictions when a small 'cohesive fraction' is present on site? Can we successfully implement our improved understanding of the local small-scale sediment transport processes within morphological models of coastal areas? Can we provide a robust physics-based approach to predict the future of these coastal areas, and the position of the coastline itself, as the sea-level rises inexorably around us? These are now some of the challenges that coastal marine scientists face, and that need to be answered on behalf of the $50 \%$ of the world's population that now lives within $60 \mathrm{~km}$ of the shoreline.

Open Access This article is distributed under the terms of the Creative Commons Attribution Noncommercial License which permits any noncommercial use, distribution, and reproduction in any medium, provided the original author(s) and source are credited.

\section{References}

Ahmed ASM, Sato S (2001) Investigation of bottom boundary layer dynamics of movable bed by using enhanced PIV technique. Coast Eng J 43(4):239-258. doi:10.1142/S0578563401000360

Andersen KH, Fredsøe J (1999) How to calculate the geometry of vortex ripples. In: Proceedings of coastal sediments '99, American Society of Civil Engineers, Long Island NY, USA, pp 78-93

Andersen KH, Chabanol ML, van Hecke M (2001) Dynamical models for sand ripples beneath surface waves. Phys Rev E Stat Nonlin Soft Matter Phys 63(6):066308. doi:10.1103/PhysRevE.63.066308

Asano T (1990) Two-phase flow model on oscillatory sheet-flow. In: Proceedings of the 22nd international conference on coastal engineering, American Society of Civil Engineers, Delft, The Netherlands, pp 2372-2384

Bagnold RA (1956) The flow of cohesionless grains in fluids. Philos Trans R Soc Lond A 249:235-297

Bagnold RA (1966) An approach to the sediment transport problem from general physics. 442-I, Geological Survey, Washington, DC, USA

Bailard JA (1981) An energetics total load sediment transport model for plane sloping beach. J Geophys Res 86(C11):10938-10954. doi:10.1029/JC086iC11p10938 
Bailard JA, Inman DL (1981) An energetics bedload model for a plane sloping beach: local transport. J Geophys Res 86(C3):2035-2043. doi:10.1029/JC086iC03p02035

Bijker EW (1992) Mechanics of sediment transport by the combination of waves and current. In: Proceedings of the 23rd international conference on coastal engineering, American Society of Civil Engineers, Venice, Italy, pp 147-173

Block ME, Davies AG, Villaret C (1994) Suspension of sand in oscillatory flow above ripples: discretevortex model and laboratory experiments. In: Bélorgey M, Rajaona RD, Sleath JFA (eds) Sediment transport mechanisms in coastal environments and rivers, EUROMECH 310. World Scientific, Singapore, pp 37-52

Bosman JJ (1982) Concentration measurements under oscillatory motion. M1695-II and M1875. Delft Hydraulics, Delft

Brown JM, Davies AG (2007) Flood/ebb tidal dominance in an estuary: sediment transport and morphology. In: Proceedings of 5th IAHR international symposium on 'river, coastal and estuarine morphodynamics', University of Twente, Enschede, The Netherlands, 17-21 September 2007, vol 2, pp 779-787

Chesher TJ, Soulsby RL, Foley WJ (2005) Scenario testing approach and results for sand mining pits. In: Van Rijn LC, Soulsby RL, Hoekstra P, Davies AG (eds) SANDPIT, Sand transport and morphology of offshore mining pits. Aqua Publications, The Netherlands, pp I1-I14

Chung DH, van Rijn LC (2003) Diffusion approach for suspended sand transport under waves. J Coast Res 19(1):1-11

Chung DH, Grasmeijer BT, van Rijn LC (2000) Wave-related suspended sand transport in the ripple regime. In: Proceedings of the 27th international conference on coastal engineering, American Society of Civil Engineers, Sydney, Australia, pp 2836-2849

Damgaard JS, Stripling S, Soulsby RL (1996) Numerical modelling of coastal shingle transport. TR 4, HR Wallingford, Wallingford

Damgaard JS, Hall LJ, Soulsby RL (2001) General engineering sand transport model: SedFlux. In: van Rijn LC, Davies AG, van de Graaff J, Ribberink JS (eds) SEDMOC, sediment transport modelling in marine coastal environments. Aqua Publications, Amsterdam, pp CD1-CD9

Davies AG (1990) A model of the vertical structure of the wave and current bottom boundary layer. In: Davies AM (ed) Modeling marine systems, Chap. 10, vol II. CRC Press, Boca Raton, pp 263-297

Davies AG, Brown JM (2007) Field measurement and modelling of scour pit dynamics in a sandy estuary. In: Coastal sediments '07: proceedings of the 6th international symposium on coastal engineering and science of coastal sediment processes, May 2007, New Orleans, American Society of Civil Engineers, pp 1609-1622

Davies AG, Li Z (1997) Modelling sediment transport beneath regular symmetrical and asymmetrical waves above a plane bed. Cont Shelf Res 17(5):555-582. doi:10.1016/S0278-4343(96)00048-9

Davies AG, Thorne PD (2002) 1DV-model of sand transport by waves and currents in the ripple bed regime. In: Proceedings of the 28th international conference on coastal engineering, World Scientific, Cardiff, UK, pp 2599-2611

Davies AG, Thorne PD (2005) Modelling and measurement of sediment transport by waves in the vortex ripple regime. J Geophys Res 110:C05017. doi:1029/2004JC002468, 25 pp

Davies AG, Villaret C (1997) Oscillatory flow over rippled beds: Boundary layer structure and waveinduced Eulerian drift. In: Hunt JN (ed) Gravity waves in water of finite depth, advances in fluid mechanics. Advances in fluid mechanics. Computational Mechanics Publications, Southampton, pp 215-254

Davies AG, Villaret C (1999) Eulerian drift induced by progressive waves above rippled and very rough beds. J Geophys Res 104(C1):1465-1488. doi:10.1029/1998JC900016

Davies AG, Villaret C (2002) Prediction of sand transport rates by waves and currents in the coastal zone. Cont Shelf Res 22(18-19):2725-2737. doi:10.1016/S0278-4343(02)00123-1

Davies AG, Villaret C (2003) Sediment transport modelling for coastal morphodynamics. In: Proceedings of coastal sediments '03, May 18-23, Clearwater, Florida, East Meets West Productions, 14 pp

Davies AG, Soulsby RL, King HL (1988) A numerical model of the combined wave and current bottom boundary layer. J Geophys Res 93(C1):491-508. doi:10.1029/JC093iC01p00491

Davies AG, Ribberink JS, Temperville A, Zyserman JA (1997) Comparisons between sediment transport models and observations made in wave and current flows above plane beds. Coast Eng 31(1-4):163198. doi:10.1016/S0378-3839(97)00005-7

Davies AG, van Rijn LC, Damgaard JS, van de Graaff J, Ribberink JS (2002) Intercomparison of research and practical sand transport models. Coast Eng 46(1):1-23. doi:10.1016/S0378-3839(02)00042-X

Davies AG, Berx BE, Brown JM, Villaret C (2005) Morphological modeling of trenches and pits in wavecurrent flows. In: Van Rijn LC, Soulsby RL, Hoekstra P, Davies AG (eds) SANDPIT, sand transport and morphology of offshore mining pits. Aqua Publications, The Netherlands, pp AS1-AS14 
Dibajnia M, Watanabe A (1992) Sheet flow under nonlinear waves and currents. In: Proceedings of the 23rd international conference on coastal engineering, American Society of Civil Engineers, Venice, Italy, pp 2015-2028

Dohmen-Janssen CM (1999) Grain size influence on sediment transport in oscillatory sheet flow: phase lags and mobile-bed effects. Ph.D. Thesis, Delft University of Technology, Delft, The Netherlands, $246 \mathrm{pp}$

Dohmen-Janssen CM, Hassan WN, Ribberink JS (2001) Mobile-bed effects in oscillatory sheet flow. J Geophys Res 106(C11):27103-27115. doi:10.1029/2000JC000513

Dong P, Zhang K (2002) Intense near-bed sediment motions in waves and currents. Coast Eng 45(2):75-87. doi:10.1016/S0378-3839(02)00040-6

Eidsvik KJ (2006) Large scale modelling of oscillatory flows over rippled bottom. Cont Shelf Res 26:318337. doi:10.1016/j.csr.2005.11.005

Englelund F, Fredsøe J (1976) A sediment transport model for straight alluvial channels. Nord Hydrol 7:293-306

European Commission (2006) Maritime facts and figures. Document KL-75-06-396-EN-C, $11 \mathrm{pp}$

Fredsøe J (1984) Turbulent boundary layer wave-current motion. J Hydraul Eng 110(8):1103-1120

Fredsøe J, Deigaard R (1992) Mechanics of coastal sediment transport. Advanced series on ocean engineering, vol 3. World Scientific, Singapore, $369 \mathrm{pp}$

Glenn SM, Grant WD (1987) A suspended sediment stratification correction for combined wave and current flows. J Geophys Res 92(C8):8244-8264. doi:10.1029/JC092iC08p08244

Grant WD, Madsen OS (1979) Combined wave and current interaction with a rough bottom. J Geophys Res 84(C4):1797-1808. doi:10.1029/JC084iC04p01797

Grant WD, Madsen OS (1982) Movable bed roughness in unsteady oscillatory flow. J Geophys Res 87(NC1):469-481. Oceans and atmospheres. doi:10.1029/JC087iC01p00469

Grant WD, Madsen OS (1986) The continental-shelf bottom boundary layer. Annu Rev Fluid Mech 18:265305. doi:10.1146/annurev.fl.18.010186.001405

Hansen EA, Fredsøe J, Deigaard R (1994) Distribution of suspended sediment over wave-generated ripples. J Waterw Port Coast Ocean Eng 120(1):37-55. doi:10.1061/(ASCE)0733-950X(1994)120:1(37)

Heathershaw AD (1974) "Bursting" phenomena in the sea. Nature 248(5447):394-395. doi:10.1038/ $248394 \mathrm{a} 0$

Hervouet J-M, Bates P (2000) The TELEMAC modelling system. Hydrol Process 14(13):2207-2364. Special issue. 10.1002/1099-1085(200009)14:13<2207::AID-HYP22>3.0.CO;2-B

Houwman KT, Ruessink BG (1996) Sediment transport in the vicinity of the shoreface nourishment of Terschelling. Department of Physical Geography, University of Utrecht, Utrecht

Jenkins JT, Hanes DM (1998) Collisional sheet flows of sediment driven by a turbulent fluid. J Fluid Mech 370:29-52. doi:10.1017/S0022112098001840

Kobayashi N, Seo SN (1985) Fluid and sediment interaction over a plane bed. J Hydraul Eng 111(6):903921

Li Z, Davies AG (2001) Turbulence closure modelling of sediment transport beneath large waves. Cont Shelf Res 21(3):243-262. doi:10.1016/S0278-4343(00)00089-3

Li L, Sawamoto M (1995) Multi-phase model on sediment transport in sheet-flow regime under oscillatory flow. Coast Eng J 38(2):157-178

Madsen OS, Grant WD (1976) Qualitative description of sediment transport by waves. In: Proceedings of the 12th international conference on coastal engineering, American Society of Civil Engineers, Washington, DC, USA, pp 1093-1112

Magar V, Davies AG (2005) Suspended sediment dynamics over rippled beds in oscillatory flows based on a 2DHV discrete-vortex/particle-tracking model. In: Van Rijn LC, Soulsby RL, Hoekstra P, Davies AG (eds) SANDPIT, sand transport and morphology of offshore mining pits. Aqua Publications, The Netherlands, pp AG1-AG9

Malarkey J, Davies AG (2002) Discrete vortex modelling of oscillatory flow over ripples. Appl Ocean Res 24(3):127-145. doi:10.1016/S0141-1187(02)00035-4

Malarkey J, Davies AG, Li Z (2003) A simple model of unsteady sheet flow sediment transport. Coast Eng 48(3):171-188. doi:10.1016/S0378-3839(03)00025-5

Mathisen PP, Madsen OS (1996a) Waves and currents over a fixed rippled bed. 1. Bottom roughness experienced by waves in the presence and absence of currents. J Geophys Res 101(C7):16533-16542. doi:10.1029/96JC00954

Mathisen PP, Madsen OS (1996b) Waves and currents over a fixed rippled bed. 2. Bottom and apparent roughness experienced by currents in the presence of waves. J Geophys Res 101(C7):16543-16550. doi:10.1029/96JC00955 
Mathisen PP, Madsen OS (1999) Waves and currents over a fixed rippled bed. 3. Bottom and apparent roughness for spectral waves and currents. J Geophys Res 104(C8):18447-18461. doi:10.1029/ 1999JC900114

Miles GV (1986) Numerical model simulation of entrainment of sand bed material. Hydraulics Research Report No. SR 75, March 1986, 24 pp

Murray PB, Davies AG, Soulsby RL (1991) Sediment pick-up in wave and current flows. In: Soulsby RL, Bettess R (eds) Sand transport in rivers, estuaries and the sea, EUROMECH 262. A. A. Balkema, Rotterdam, pp 37-43

Nielsen P (1979) Some basic concepts of wave sediment transport. Techn. Univ. Denmark, Inst. Hydrodyn. Hydraul. Engng, 20, 160 pp

Nielsen P (1988) Three simple models of wave sediment transport. Coast Eng 12(1):43-62. doi: 10.1016/0378-3839(88)90014-2

Nielsen P (1992) Coastal bottom boundary layers and sediment transport. Advanced series on ocean engineering, vol 4. World Scientific, Singapore, $324 \mathrm{pp}$

Nielsen P, Teakle IAL (2004) Turbulent diffusion of momentum and suspended particles: a finite-mixinglength theory. Phys Fluids 16(7):2342-2348. doi:10.1063/1.1738413

Perrier G (1996) Numerical modelling of the transport of non-cohesive sediments by waves and current over a rippled bed. Ph.D. Thesis, Orsay University, Paris, France, 380 pp

Ribberink JS (1998) Bed-load transport for steady flows and unsteady oscillatory flows. Coast Eng 34(1-2): 59-82. doi:10.1016/S0378-3839(98)00013-1

Ribberink JS, Al-Salem AA (1995) Sheet flow and suspension of sand in oscillatory boundary layers. Coast Eng 25(3-4):205-225. doi:10.1016/0378-3839(95)00003-T

Sato S, Horikawa K (1986) Laboratory study on sand transport over ripples due to asymmetric oscillatory flows. In: Proceedings of the 20th international conference on coastal engineering, American Society of Civil Engineers, Taipei, Taiwan, pp 1481-1495

Shennan I (1989) Holocene crustal movements and sea-level changes in Great Britain. J Quaternary Sci 4(1):77-89. doi:10.1002/jqs.3390040109

Sleath JFA (1991) Velocities and shear stresses in wave-current flows. J Geophys Res 96(C8):15237-15244. doi:10.1029/91JC01458

Soulsby RL (1987) The relative contributions of waves and tidal currents to marine sediment transport. Hydraulics Research Report SR 125, 20 pp

Soulsby RL (1997) Dynamics of marine sands: a manual for practical applications. Telford, London $249 \mathrm{pp}$

Soulsby RL, Malarkey J (2005) Net transport rates at Teignmouth, UK. In: Van Rijn LC, Soulsby RL, Hoekstra P, Davies AG (eds) SANDPIT, sand transport and morphology of offshore mining pits. Aqua Publications, The Netherlands, pp D1-D8

Soulsby RL, Whitehouse RJS (2005) Prediction of ripple properties in shelf seas, Technical Report TR 154, HR Wallingford

Styles R, Glenn SM (2002) Modeling bottom roughness in the presence of wave-generated ripples. J Geophys Res 107(C8). doi:10.1029/2001JC000864

Sumer BM, Kozakiewicz A, Fredsøe J, Deigaard R (1996) Velocity and concentration profiles in sheet-flow layer of movable bed. J Hydraul Eng 122(10):549-558. doi:10.1061/(ASCE)0733-9429(1996) 122:10(549)

Thorne PD, Hanes DM (2002) A review of acoustic measurements of small-scale sediment processes. Cont Shelf Res 22:603-632. doi:10.1016/S0278-4343(01)00101-7

Thorne PD, Davies AG, Williams JJ (2002a) Measurements of bedforms and sediments in suspension under waves. In: Proceedings of the 28th international conference on coastal engineering, American Society of Civil Engineers, Cardiff, UK, pp 3007-3019

Thorne PD, Williams JJ, Davies AG (2002b) Suspended sediments under waves measured in a large-scale flume facility. J Geophys Res 107(C8). doi:10.1029/2001JC000988

Thorne PD, Davies AG, Williams JJ (2003a) Measurements of intra-wave sediment entrainment over a rippled bed. In: Proceedings of coastal sediments '03, East Meets West Productions, Clearwater FL, USA

Thorne PD, Davies AG, Williams JJ (2003b) Measurements of near-bed intra-wave sediment entrainment above vortex ripples. Geophys Res Lett 30(20). doi:10.1029/2003GL018427

Van Rijn LC (1993) Principles of Sediment Transport in Rivers, Estuaries and Coastal Seas. Aqua Publications, Amsterdam

Van Rijn LC (2005) Prediction of bed roughness and sand transport in combined steady and oscillatory flow using the TR2004 model. In: Van Rijn LC, Soulsby RL, Hoekstra P, Davies AG (eds) SANDPIT, sand transport and morphology of offshore mining pits. Aqua Publications, The Netherlands, pp AC1-AC13 
Van Rijn LC (2007a) Unified view of sediment transport by currents and waves. 1: Initiation of motion, bed roughness and bed-load transport. J Hydraul Eng 133(6):649-667. doi:10.1061/(ASCE)07339429(2007)133:6(649)

Van Rijn LC (2007b) Unified view of sediment transport by currents and waves. 2: Suspended transport. J Hydraul Eng 133(6):668-689. doi:10.1061/(ASCE)0733-9429(2007)133:6(668)

Van Rijn LC (2007c) Unified view of sediment transport by currents and waves. 3: Graded beds. J Hydraul Eng 133(7):761-775. doi:10.1061/(ASCE)0733-9429(2007)133:7(761)

Van Rijn LC, Soulsby RL, Hoekstra P, Davies AG (2005) SANDPIT, sand transport and morphology of offshore mining pits. Aqua Publications, The Netherlands $716 \mathrm{pp}$

Van Rijn LC, Ruessink G, Grasmeijer B, van der Werf J, Ribberink J (2007a) Wave-related transport and nearshore morphology. In: Coastal sediments '07: proceedings of the 6th international symposium on coastal engineering and science of coastal sediment processes, May 2007, New Orleans, American Society of Civil Engineers, pp 1-14

Van Rijn LC, Walstra D-JR, van Ormondt M (2007b) Unified view of sediment transport by currents and waves. 4: Application of morphodynamic model. J Hydraul Eng 133(6):776-793. doi:10.1061/ (ASCE)0733-9429(2007)133:7(776)

Villaret C, Davies AG (1995) Modelling sediment-turbulent flow interactions. Appl Mech Rev 48(9): 601-609

Villard PV, Osborne PD (2002) Visualization of wave-induced suspension patterns over two-dimensional bedforms. Sedimentology 49:363-378. doi:10.1046/j.1365-3091.2002.00448.x

Villaret C, Davies AG, Frey JM (2000) Sand transport rate predictions using a two-phase flow model. In: Proceedings of the 27th international conference on coastal engineering, American Society of Civil Engineers, Sydney, Australia, pp 2561-2574

Vincent CE, Hanes DM (2002) The accumulation and decay of near-bed suspended sand concentration due to waves and wave groups. Cont Shelf Res 22(14):1987-2000. doi:10.1016/S0278-4343(02)00051-1

Vincent CE, Marsh SW, Webb MP, Osborne PD (1999) Spatial and temporal structures of suspension and transport over megaripples on the shore face. J Geophys Res 104(C5):11215-11224. doi:10.1029/ 1999JC900020

Walstra D-JR, Chesher T, Davies AG, Ribberink J, Sergent P, Silva P et al (2005) Intercomparison of the state of the morphological models. In: Van Rijn LC, Soulsby RL, Hoekstra P, Davies AG (eds) SANDPIT, sand transport and morphology of offshore mining pits. Aqua Publications, The Netherlands, pp AY1-AY23

Wang ZB, Ribberink JS (1986) The validity of a depth-integrated model for suspended sediment transport. J Hydraul Res 24(1):53-67

Web 1 Old Hallsands-the story of its destruction. http://www.hallsands.org.uk/

Wilson KC (1989) Mobile-bed friction at high shear stress. J Hydraul Eng 115(6):825-830

Wolf J, Woolf DK (2005) Waves and climate change in the Sea of the Hebrides. In: Proceedings of 15th (2005) ISOPE conference, int. soc. of offshore and polar eng., Seoul, 8 pp

Wolf J, Woolf DK (2006) Waves and climate change in the north-east Atlantic. Geophys Res Lett 33:L06604. doi:10.1029/2005GL025113, 4 pp

Zedler EA, Street RL (2001) Large-eddy simulation of sediment transport: Currents over ripples. J Hydraul Eng 127(6):444-452. doi:10.1061/(ASCE)0733-9429(2001)127:6(444)

Zyserman JA, Fredsøe J (1994) Data analysis of bed concentration of suspended sediment. J Hydraul Eng 120(9):1021-1042. doi:10.1061/(ASCE)0733-9429(1994)120:9(1021) 